\title{
Fluorescence of solutions: A review
}

\author{
R. T. WILLIAMS AND J. W. BRIDGES \\ From the Department of Biochemistry, St. Mary's Hospital \\ Medical School, London
}

The use of fluorescence as an analytical technique in clinical biochemistry and pathology is in the process of developing and it is therefore important that those who use it should understand the underlying principles governing the phenomenon of fluorescence and its application, so that this elegant and sensitive technique can be used to its greatest advantage. Fluorescence has been studied by physicists and photochemists for over a century but the results of these studies have penetrated but slowly into biology and medicine, partly due to difficulties of communication and partly because the compounds, temperatures, and solvents used were of little interest from the biological point of view.

Present-day research in medicine and biochemistry requires many highly sensitive analytical techniques and workers in these fields frequently have to develop their own physical instruments to meet the needs of their researches. This type of development has occurred in the field of fluorescence, for the first commercial spectrofluorimeter (Aminco-Bowman spectrophotofluorometer; see section on fluorimeters) was based upon a model devised by a medically qualified scientist, Dr. R. L. Bowman (Bowman, Caulfield, and Udenfriend, 1955). With this instrument is it possible to measure not only visible but also ultraviolet fluorescence, and to record the wavelengths of maximum fluorescence and of maximum excitation or activation. Some vitamins and drugs have been assayed fluorimetrically for many years (Bowen and Wokes, 1953) but this earlier work was done with filter fluorimeters which are less sensitive and less selective than the modern spectrofluorimeters (or fluorescence spectrometers) and usually only measure visible fluorescence.

Fluorescence is a highly sensitive analytical tool which can be used to measure concentrations as low as $10^{-8}$ to $10^{-10} \mathrm{~g} . / \mathrm{ml}$. $(0.01$ to $0.0001 \mu \mathrm{g} . / \mathrm{ml}$.) whereas few substances can be estimated colorimetrically below $10^{-7} \mathrm{~g} . / \mathrm{ml}$. $(0 \cdot 1 \mu \mathrm{g} . / \mathrm{ml}$.). Since the use of fluorescence in analysis is in its infancy one can expect improvements in instrumentation such as better detectors of fluorescence and better light sources. There is no doubt that fluorescence analysis will become even more sensitive and more accurate than it is at present.

\section{THE MECHANISM OF FLUORESCENCE}

In this section is it proposed to give a simplified account of the origin of fluorescence and to give some guidance as to what sort of molecules one could expect to fluoresce. Fluorescence is essentially an electronic phenomenon and is primarily concerned with light of wavelengths in the region of 200 to $800 \mathrm{~m} \mu$. Some compounds when illuminated with light of this region only absorb specific wavelengths of this light and the wavelengths absorbed are characteristic of the particular compound being examined. The extent to which the light of these wavelengths is absorbed constitutes the absorption spectrum of the compound. As a consequence of the absorption of light some of the molecules of the compound become excited because certain electrons in the molecule are raised to a higher energy level. This is shown diagrammatically in Figure 1. The energy levels ${ }^{1}$ are represented in Fig. 1 by horizontal lines and the directions of the energy transitions by vertical or inclined arrows. On absorption of light, the molecule is raised from the ground state $G$ to the excited state $\mathrm{E}$ as indicated by the vertical arrow A. The molecule returns to the ground state, emitting some of its absorbed energy as fluorescence, as indicated by the arrow marked F. An electronic transition due to light absorption is almost instantaneous $\left(10^{-15}\right.$ second), whereas the lifetime of the excited state is about $10^{-8}$ second, and therefore, the whole process of light absorption and fluorescence emission takes place in about $10^{-8}$ second. Now some of the absorbed energy is lost partly by collisions with other molecules and partly by other means, so that less energy is emitted as fluorescence than was absorbed from the exciting light. According to the quantum theory, light is absorbed in discrete units called quanta and the energy ( $E)$ of a quantum is related to vibrational frequency $(\nu)$, thus:-

${ }^{1}$ To simplify the picture only the lowest vibrational level of each energy level is shown. 


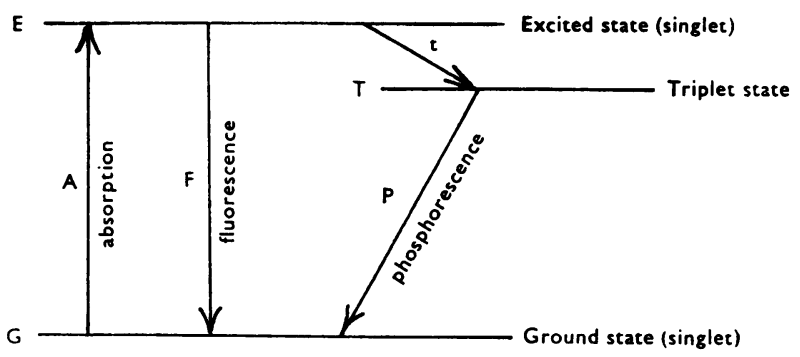

FIG. 1. Diagram relating energy levels, absorption, fluorescence, and phosphorescence.

$\mathrm{E}=\mathrm{h} \nu$, where $\mathrm{h}=$ Planck's constant. Frequency is related to wavelength $(\lambda)$ according to the expression, $v=\frac{\mathrm{c}}{\lambda}$, where $\mathrm{c}$ is the velocity of light. From these two equations, $E=\frac{h c}{\lambda}$, and, since $h$ and $c$ are constants, $E$ varies inversely as $\lambda$. As mentioned above, the energy emitted as fluorescence is less than the light energy absorbed and therefore from the last equation the wavelength of fluorescence is longer than that of the absorbed light.

The mechanism of phosphorescence is also illustrated in Figure 1. This phenomenon is distinguished from fluorescence by the much longer life time of the excited state (which may be up to several seconds). To understand the reason for this difference one must consider the spin of the electrons of a molecule. Electrons in most molecules are found in even numbers and are paired. In each pair, the two electrons spin about their own axes in opposite directions (anti-parallel spins, see below) and, for reasons which need not be considered here, such molecules are said to have a 'singlet' electronic level. When the molecule is raised to the excited state two things could happen: (1) the electrons may remain 'singlet' and the molecule can then return to the ground state with the emission of fluorescence (path F), or, (2) one electron, by some internal energy transition, may have its spin reversed (parallel spins, see below) and the molecule is then said to have a 'triplet' electronic level:-

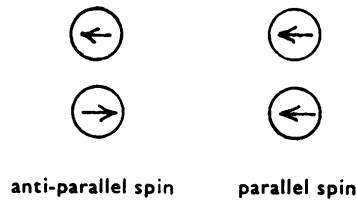

In Fig. 1, this change in indicated by the top inclined arrow $t$ and the 'triplet' excited state is indicated by the horizontal line T. Such a molecule is regarded to be in a metastable state. The life time of the triplet excited state is longer than that of the singlet excited state, for the molecule has to return to the ground singlet state by what is known as a 'forbidden transition' which has a low probability. ? During this return there is emission of phosphor- $\vec{v}$ escence as indicated by the inclined arrow P. In the $P$ transition from the singlet excited state to the triplet state there is a loss of energy, for the energy level $\mathrm{T} \vec{\circ}$ is lower than E. Therefore, there is less energy $\frac{}{2}$ emitted in the transition from $T$ to $G$, so that the $\vec{c}$ wavelength of phosphorescence is longer than the wavelength of the fluorescence that would have been produced by the same excitation. Fluorescence is $\mathscr{O}$ thus an emission from a singlet excited state (electron : spin paired) whereas phosphorescence is emission from a triplet excited state (electrons unpaired). Phosphorescence persists longer than fluorescence and this persistence is prolonged and the intensity $\stackrel{2}{\circ}$ enhanced by low temperatures. The biological $\stackrel{\Phi}{\circ}$ applications of phosphorescence are as yet limited.

FLUORESCENT COMPOUNDS An examination of the literature shows that not all organic compounds are음 fluorescent. However, those which show fluorescence are usually aromatic or contain conjugated double? bonds (i.e., alternating single and double bonds $\frac{5}{3}$ between atoms). Since fluorescence is an electronic phenomenon, it might be expected that those $\bigcirc$ molecules containing electrons which undergo

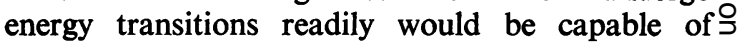
fluorescing. Such electrons are $(a)$ the so-called $\rightarrow$ ' $\pi$ ', 'mobile', or 'delocalized', electrons and $(b)$ the 'lone pair' electrons ${ }^{2}$. The nature of $\pi$-electrons may $N$ be explained briefly as follows. The application of $N$ quantum mechanics to molecular theory has shown $\stackrel{N}{N}$ that substances containing two or more conjugated $\omega$ double bonds (i.e., $-\mathrm{C}=\mathrm{C} . \mathrm{C}=\mathrm{C}-$, etc.) have $\mathrm{a} 2$ certain number of electrons possessing greater mobility than the other electrons (i.e., $\sigma$ electrons) of the molecule. One of these $\pi$-electrons is derived from ${ }^{+}$ each carbon atom associated with the double bond, $\frac{T}{\circ}$ and these electrons form a cloud which circulates $\frac{\overrightarrow{\mathrm{D}}}{\mathrm{O}}$ the molecule (Fig. 2). Thus benzene, which has six $\frac{\odot}{\odot}$ 'The 'lone pair' is a pair of electrons not directly concerned in chemical bonding and they are found particularly associated with $\mathbf{N}, \mathbf{O}, \mathbf{P}$, and $\mathbf{S}$ atoms in compounds. They may interact with $\pi-$ electrons to increase an electron cloud, but usually on excitation they? yield phosphorescence rather than fluorescence (Kasha, 1960). 
carbon atoms and the equivalent of three conjugated double bonds, has six of these electrons whose orbits form a cloud above and below the molecule. None of these electrons has any special relation to one particular carbon atom, but all six electrons are equally related to all six carbon atoms. The other electrons of the molecule, termed $\sigma$ electrons, are localized and tend to be located along the line joining the nuclei of the two participating atoms. The freedom of the $\pi$-electrons, however, can be influenced by substituent groups and, in heterocyclic systems, by heteroatoms, i.e., atoms other than carbon, such as $\mathrm{O}, \mathrm{N}$, and $\mathrm{S}$, so that the $\pi$-electrons become relatively more or less delocalized under their influence.

$$
\begin{aligned}
& \text { a) }-\mathrm{C}=\mathrm{C}-\mathrm{C}=\mathrm{C}- \\
& \text { b) } \mathrm{C}: \mathrm{C}: \mathrm{C}: \mathrm{C}: \\
& \text { c) }: \stackrel{\mathrm{C}: \mathrm{C}: \mathrm{C}: \mathrm{C}:}{\longrightarrow} \leftarrow \text {-electron cloud }
\end{aligned}
$$

FIG. 2. Diagram showing the $\pi$-electrons of conjugated double bonds.

(a) Formal way of showing conjugated double bonds

(b) The electrons of the bonds

(c) Representation of the $\pi$-electrons; the electrons between the $C$ atoms are the $\sigma$ electrons.

If a compound contains $\pi$-electrons there is a good possibility that it will fluoresce, and if a substituent, which increases the freedom of these electrons, is added to the compound, then the substituted compound is likely to be more fluorescent than the unsubstituted parent compound. On the other hand, if the substituent tends to localize the $\pi$-electrons, there will be a diminution or abolition of fluorescence. Let us take the simple examples of cyclohexane, benzene, and vitamin A. Cyclohexane contains no conjugated double bonds and is non-fluorescent. Benzene is an aromatic compound and is weakly fluorescent. Vitamin $\mathbf{A}$ is not aromatic, but contains five conjugated double bonds and is therefore fluorescent (see below):-

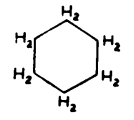

Cyclohexane, nonfluorescent no absorption peak
It will be noted that the excitation maximum of benzene has a longer wavelength than the absorption peak, whereas the excitation of vitamin $A$ is fairly close to the absorption peak. Theoretically the absorption and excitation peaks should coincide, and the differences that occur are due to instrumental errors largely as a result of the variation in energy output with wavelength of the light source used for excitation (see p. 16 and Fig. 11). These errors can be corrected if necessary and when these corrections are made the excitation maximum is found to be close to the absorption peak.

The effects of substituents upon fluorescence can be illustrated with benzene, aniline, and nitrobenzene. In dilute solutions in water, aniline is 40 to 50 times more fluorescent than benzene, whereas nitrobenzene is non-fluorescent (Bridges and Williams, 1962).
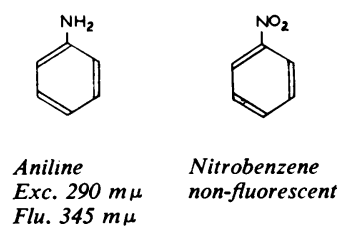

The $\mathrm{NH}_{2}$ group in aniline tends to activate the benzene ring and thus increases the freedom of the $\pi$-electrons. The $\mathrm{NO}_{2}$ group in nitrobenzene, on the other hand, deactivates the ring by tending to withdraw the $\pi$-electrons from the ring thus reducing their freedom by increasing their localization. Now the $\mathrm{NH}_{2}$ group is one of the classical ortho-paradirecting groups and the $\mathrm{NO}_{2}$ group is one of the classical meta-directing groups, so that one might conclude that mono-substituted benzenes containing ortho-para-directing groups are fluorescent whereas those containing meta-directing groups are nonfluorescent. This conclusion is partly, but not wholly, true, as can be seen from Table I.

The data quoted in Table I were obtained in this laboratory (Bridges and Williams, 1962; 1963) with the Aminco-Bowman spectrofluorimeter and it is important to indicate how much of the compounds quoted were needed to produce fluorescence. Benzene, ethylbenzene, and chlorobenzene are weakly fluorescent and with the first two at least 20 to $25 \mu \mathrm{g}$. $/ \mathrm{ml}$. was needed to detect fluorescence, whilst with chlorobenzene at least $500 \mu \mathrm{g} . / \mathrm{ml}$. was needed. With aniline and phenol, fluorescence could be detected down to concentrations of 0.01 $\mu \mathrm{g} . / \mathrm{ml}$. The main points about this table are that aromatic compounds containing $\mathrm{NH}_{2}, \mathrm{OH}, \mathrm{F}$, $\mathrm{OCH}_{3}, \mathrm{NHCH}_{3}$, and $\mathrm{N}\left(\mathrm{CH}_{3}\right)_{2}$ groups are likely to be fluorescent, whilst those containing $\mathrm{Cl}, \mathrm{Br}, \mathrm{I}$, 
TABLE I

FLUORESCENCE OF MONOSUBSTITUTED BENZENES ${ }^{1}$ (BRIDGES AND WILLIAMS, 1963)

Compound

$\mathrm{C}_{6} \mathrm{H}_{5} \mathrm{R}$

\begin{tabular}{llll}
\hline Substituent $R$ & Excitation & Fluorescence & Relative Intensity \\
&
\end{tabular}

$(\lambda \max . m \mu)$

$(\lambda \max . m \mu)$

Ortho-para-directing

Benzene

Aniline

Monomethylaniline

Dimethylaniline

Acetanilide

Fluorobenzene

Chlorobenzene

Bromobenzene

Iodobenzene

Toluene

Ethylbenzene

Phenol

Anisole

Phenoxide ion

$\mathrm{H}$
$\mathrm{NH}_{2}$
$\mathrm{NHCH}_{3}$
$\mathrm{~N}_{\left(\mathrm{CH}_{3}\right)_{2}}$
$\mathrm{NHCOCH}$
$\mathrm{F}$
$\mathrm{Cl}$
$\mathrm{Br}$
$\mathbf{I}$
$\mathrm{CH}_{3}$
$\mathrm{C}_{2} \mathrm{H}_{5}$
$\mathrm{OH}$
$\mathrm{OCH}_{3}$
$\mathrm{O}^{-}$

269
290
290
297
-
265
281
-
-
273
275
282
279

291
345
360
363
None
285
294
None
None
292
292
330
302
None

1
46
-114
0
13
$0 \cdot 02$
0
0
$3 \cdot 8$
$1 \cdot 2$
112
92
0

Meta-directing

Benzoic acid

Benzoate ion

Nitrobenzene

Benzene sulphonic acid

$\mathrm{COOH}$
$\mathrm{COO}^{-}$
$\mathrm{NO}_{2}$
$\mathrm{SO}_{3} \mathrm{H}$
$\mathrm{SO}_{2} \mathrm{NH}_{2}$
$\mathrm{CHO}$
$\mathrm{AsO}_{3} \mathrm{H}_{2}$
$\mathrm{CN}$

$\overline{\bar{~}}$

None
None
None
None
None
None
None
294

Benzenearsonic acid

Benzonitrile

${ }^{1}$ The wavelengths giv containing ethanol. containing ethanol.
practical values.

$\mathrm{NHCOCH}_{3}$ and most of the meta-directing groups, except $\mathrm{CN}$, are likely to be weakly fluorescent or non-fluorescent. The quenching effect (see also p. 14) of bromo and iodo substituents upon fluorescence is well illustrated with the highly fluorescent dye, fluorescein. The quantum efficiency ${ }^{3}$ of fluorescence of fluorescein is $70 \%$, that of its tetrabromo derivative, eosin, is $15 \%$, and that of its tetra-iodo derivative, erythrosine, is $3 \%$ (Bowen and Wokes, 1953).

So far, the effect of single substituents upon the fluorescence of benzene has been examined, and now consideration must be given to the effect of more than one substituent. At present, there is little systematic data pertaining to the fluorescence of disubstituted benzenes. However, some information has been obtained in this laboratory (Bridges and Williams, 1962) which suggests that the fluorescence of these molecules depends upon the resultant of the combined action of both substituents upon the $\pi$-electrons. The results are complicated, for some meta-directing groups, which normally abolish the fluorescence of benzene, when combined

${ }^{3}$ The quantum efficiency of fluorescence is a measure of the number of excited molecules returning to the ground state by emission of fluorescence along path F (Fig. 1). If all the excited molecules fluorescence along path $F$ (Fig. 1). If all the excited molecules never been observed. In Table I, no compound has a quantum efficiency of more than $10 \%$. with ortho-para-directing groups which normally $\stackrel{\mathbb{2}}{\Rightarrow}$ increase the fluorescence of benzene, may produce $\frac{3}{3}$ more or less fluorescence than the ortho-paradirecting groups alone, as shown in the examples given in Table II.

It will be noted that benzenesulphonamide, which contains the weak meta-directing sulphonamideo group, is non-fluorescent, but when combined with: an amino group as in sulphanilamide ( $p$-aminobenzenesulphonamide), the resulting compound is $₹$ five times as fluorescent as aniline. On the other hand, 을 the weak ortho-para-directing chloro group in chlorobenzene suppresses the fluorescence of benzene to a very small value, and in combinationn with an amino group in $p$-chloroaniline, the fluor=escence of aniline is also reduced. Nitrobenzene is 0 non-fluorescent, and, if the strongly meta-directingew nitro group is combined with an amino group as in $p$-nitroaniline, the effect of the nitro group iso sufficient to make p-nitroaniline non-fluorescent $\Phi$ The effect of more than one substituent on fluor? escence is thus a resultant effect upon the mobility or freedom of the $\pi$-electrons. Weak meta-directing groups, such as $\mathrm{SO}_{3} \mathrm{H}$ and $\mathrm{SO}_{2} \mathrm{NH}_{2}$, can, in combin ation with strong ortho-para-directing groups $\left(\mathrm{NH}_{2}, \mathrm{OH}\right)$, often increase fluorescence by increasing the freedom (perhaps one could say chaos) of the $\pi$-electrons. A strong meta-directing group (excep? 
TABLE II

FLUORESCENCE OF SOME DISUBSTITUTED BENZENES COMPARED WITH REL.ATED MONOSUBSTITUTED BENZENES (BRIDGES AND WILLIAMS, 1962)

\begin{tabular}{|c|c|c|c|c|c|}
\hline Compound & $R$ & $R^{1}$ & Excitation & Fluorescence & Relative Intensity ${ }^{1}$ \\
\hline $\begin{array}{l}\text { Aniline } \\
\text { Benzenesulphc namide } \\
\text { Sulphanilamide } \\
\text { Chlorobenzene } \\
p \text {-Chloroaniline } \\
\text { Nitrobenzene } \\
p \text {-Nitroaniline }\end{array}$ & $\begin{array}{l}\mathrm{NH}_{2} \\
\mathrm{H} \\
\mathrm{NH}_{2} \\
\mathrm{H} \\
\mathrm{NH}_{2} \\
\mathrm{H} \\
\mathrm{NH}_{2}\end{array}$ & $\begin{array}{l}\mathrm{H} \\
\mathrm{SO}_{2} \mathrm{NH}_{2} \\
\mathrm{SO}_{2} \mathrm{NH}_{2} \\
\mathrm{Cl} \\
\mathrm{Cl} \\
\mathrm{NO}_{2} \\
\mathrm{NO}_{2}\end{array}$ & $\begin{array}{l}290 \\
\overline{275} \\
281 \\
300 \\
-\end{array}$ & $\begin{array}{l}350 \\
\text { None } \\
350 \\
294 \\
360 \\
\text { None } \\
\text { None }\end{array}$ & $\begin{array}{c}46 \\
0 \\
220 \\
0 \cdot 02 \\
32 \\
0 \\
0 \\
{ }^{1} \text { Benzene }=\end{array}$ \\
\hline
\end{tabular}

CN) ${ }^{4}$ will usually tend to diminish or suppress fluorescence. A good example is the nitro group, for most simple nitro derivatives are non-fluorescent. Two examples are shown below. Diphenyloxazole (PPO) (Ott, Hayes, Hansbury, and Kerr, 1957) is fluorescent but its nitro derivative is not.

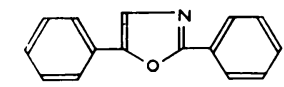

2, 5-Diphenyloxazole (PPO) fluorescent ( flu: 365 and $381 \mathrm{m \mu}$ in toluene)

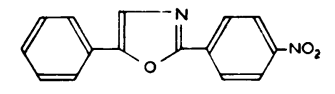

2-Phenyl-5 (p-nitrophenyl) oxazole non-fluorescent
(Diphenyloxazole derivatives are used for scintillation counting which depends on the fluorescence of the scintillator when excited by radioactivity. The scintillator POPOP is 2,2'-p-phenylenebis(5-phenyloxazole) which has a fluorescence efficiency approaching $100 \%$.)

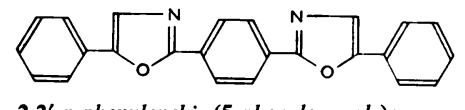

2,2'-p-phenylenebis-(5-phenyloxazole); POPOP ( $f u$ : 420 and $440 \mathrm{~m} \mu$ in toluene)

Nevertheless, if there is sufficient conjugation in the molecule to overcome the effect of the nitro group, a molecule containing a nitro group can be fluorescent, as in the case of 5-dimethylamino-4'-nitrostilbene below (Lippert, Lüder, and Moll, 1959).

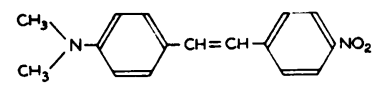

Fluorescent ( $\lambda$ max. ca. $740 \mathrm{m \mu}$ in isobutanol)

Again benzoic acid, which contains the $m$ directing $\mathrm{COOH}$ group, is non-fluorescent, but in combination with the $\mathrm{OH}$ group, as in the hydroxy-

'The $\mathrm{CN}$ group has a triple bond, i.e., $\mathrm{C} \equiv \mathrm{N}$, and the electrons of this bond can interact with the $\pi$-electron cloud of the benzene ring to produce the conditions for fluorescence. benzoic acids or the $\mathrm{NH}_{2}$ group as in the aminobenzoic acids, is does not abolish fluorescence and in some cases, e.g. $o$-hydroxybenzoic (salicylic) acid and $o$-aminobenzoic (anthranilic) acid, the fluorescence is greater than that of either phenol or aniline.

In polycyclic aromatic systems, the number of $\pi$-electrons available is greater than in benzene and therefore these compounds and their derivatives are usually much more fluorescent than benzene and its derivatives. Naphthalene, anthracene, and biphenyl derivatives, for example, are much more fluorescent than the corresponding fluorescent benzene derivatives.

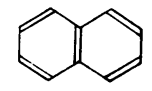

Naphthalene ( $f$ lu: ca. 323, $340 m \mu$ in ethanol; Parker and Rees, 1962)

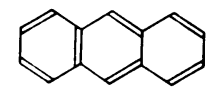

Anthracene (flu: ca. $372,400,425 \mathrm{m \mu}$ in ethanol; Parker and Rees, 1962)

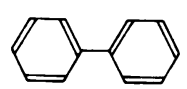

Biphenyl ( fu: 318 $m \mu$ in ethanol; Bridges, Creaven, and Williams, 1963)
The fluorescence of heterocyclic systems depends upon the nature of the hetero atom and upon substituents. The hetero atoms or groups usually encountered are $-\mathrm{N}=,>\mathrm{NH},-\mathrm{O}-$, and $-\mathrm{S}-$. Doubly bound nitrogen, i.e., $-\mathrm{N}=$, in a heterocyclic system tends to deactivate the ring by drawing the $\pi$ electrons towards it. Such rings are said to be $\pi$-deficient. Heterocyclic systems containing doubly bound nitrogen tend to be non-fluorescent unless there are substituents present which counteract the effect. Thus pyridine is non-fluorescent (Kerr, Hayes, and Ott, 1957), whereas 3-hydroxypyridine is fluorescent (Bridges, Davies, and Williams, 1963), because of the effect of the electron-donating $\mathrm{OH}$ group.<smiles>c1ccncc1</smiles>

Pyridine non-fluorescent

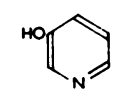

3-Hydroxypyridine fuorescent (see p. 20) 
When $>\mathrm{NH},-\mathrm{O}-$, and $-\mathrm{S}-$ occur in the heterocyclic system, there is a tendency for them to contribute to the $\pi$-electron system. Such rings are called $\pi$-excessive and the order of contribution is $-\mathrm{NH}->-\mathrm{O}->-\mathrm{S}-$. There is, therefore, a tendency for compounds containing such ring systems to be fluorescent, i.e., those containing the pyrrol, furan, and thiophene rings, although the fundamental ring compounds themselves may not be fluorescent or only weakly fluorescent. When the heterocyclic<smiles>c1cc[nH]c1</smiles>

Pyrrol<smiles></smiles>

Furan<smiles>c1ccsc1</smiles>

Thiophene

system has more than one type of hetero atom, then fluorescence will depend upon the resultant of the effect of the two hetero atoms on the $\pi$-electrons, and on the effect of any substituents. Thus thiazole and isothiazole derivatives tend to be non-fluorescent because the effect of the $-\mathrm{N}=$ upon the $\pi$-electrons is greater than $-\mathbf{S}-$, but oxazole and isoxazole derivatives could be expected to fluoresce (Ott et al., 1957) because the effect of -O- is greater than $-\mathrm{N}=$. However, the substituents in heterocyclic systems play a most important role in the fluorescence of such compounds (see pp. 373 and 374).
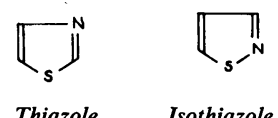

Thiazole

Isothiazole

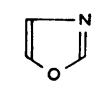

Oxazole

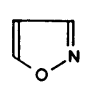

Isoxazole
CHEMICALLY INDUCED FLUORESCENCE Organic compounds which are fluorescent as such are said to possess 'native' fluorescence. It is often possible by simple chemical means to convert non-fluorescent compounds into fluorescent ones and thereby allow their detection and estimation by fluorescence. This type of fluorescence is referred to as "chemically induced' fluorescence. Thus the adrenal cortical steroid, cortisol, is non-fluorescent; in fact, an examination of its structure shows that it has an insufficient number of conjugated double bonds for fluorescence. However, if it is dissolved in concentrated sulphuric acid in the presence of ethanol, it is converted into intensely fluorescent products,

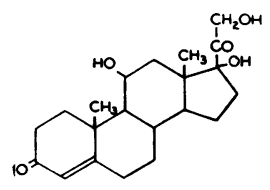

Cortisol

non-

fluorescent and, although the nature of these products ${ }^{5}$ is unknown, their fluorescence can be used for the assay of cortisol in minute quantities (Mattingly, 1962). Chemically induced fluorescence can also be used in other ways. Sometimes the 'native' fluor- $\frac{C}{0}$ escence of a compound is too weak for it to be usefulc quantitatively, but by a simple chemical reaction $\overrightarrow{\mathrm{D}}$ the compound may be converted into a highly fluorescent product which can be readily assayed ${ }^{\infty}$ fluorimetrically. Thus the tetracycline antibiotics, $\vec{\circ}$ which probably have a relatively weak native fluorescence, can be converted by calcium ions and $a_{\sigma}$ barbiturate (usually barbital) into highly fluorescentत्त complexes (Kohn, 1961), the suggested structure of one of which is shown below.

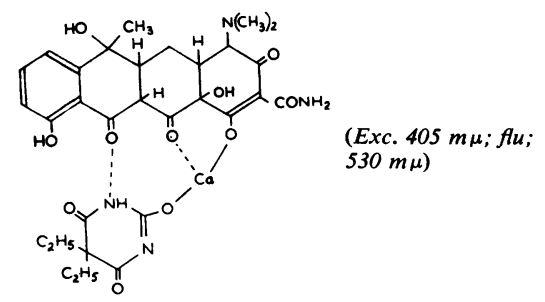

Closely related substances often have native fluorescences so similar to each other that it is impossiblea to estimate one of a group of such substances in theo presence of the others. However, it is frequently possible to convert one of these compounds intoo another fluorescent species, so that it can be estimated in the presence of its congeners. Thus adrenaline and noradrenaline show a native fluor escence which is common to most simple catechols including catechol itself. Both adrenaline and nor-음 adrenaline, however, can be oxidized at $p \mathrm{H} 6.5$ to 3,5,6-trihydroxyindoles (adrenolutine and nor-ô adrenolutine) which are highly fluorescent at alkaline $p \mathrm{H}$ values. The estimation of adrenaline? in the presence of noradrenaline can be achieved by $\$$ oxidizing at $p \mathrm{H} 3 \cdot 5$, for at this $p \mathrm{H}$ adrenaline is converted into a trihydroxyindole whereas noradrenaline is not (Udenfriend, 1962).
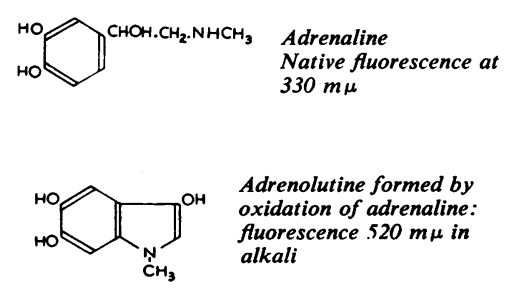

It is believed that strong sulphuric acid has the effect of introducin double bonds into the cortisol molecule. 
Changes in the $p \mathrm{H}$ of a solution will sometimes allow the differentiation of two substances with similar native fluorescence characteristics. Thus both phenol and anisole fluoresce at 300 to $310 \mathrm{~m} \mu$ at neutral $p \mathrm{H}$, but at $p \mathrm{H} 12$ phenol is converted into the non-fluorescent phenoxide ion whereas anisole remains unchanged (Rosen and Williams, 1961):-

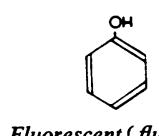

Fluorescent ( $f$ lu: 310 mu) $\mathrm{pH} 7$

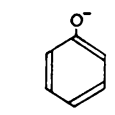
(pH 12)
Non-fluorescent

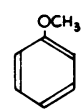

Fluorescent ( $\mathrm{flu}: 300$ $\mathrm{m \mu})$ at $\mathrm{pH} 7$ and 12
FACTORS AFFECTING FLUORESCENCE INTENSITY

The intensity of fluorescence of a compound is affected by a number of factors, the most important of which are the following: $(a)$ instrumental factors, (b) concentration, $(c)$ solvent, $(d) p \mathrm{H},(e)$ temperature, and $(f)$ stability of the compound in light. Instrumental factors are discussed in the section on fluorimeters (see p. 385).

CONCENTRATION (see also quenching p. 383) The intensity of fluorescence is proportional to the concentration of the fluorescent compound only in highly dilute solutions and therefore the concentration of the compound to be assayed is a very important consideration in quantitative work. In most fluorimeters, the fluorescence emitted from the cell holding the solution is measured at right angles to the path of the exciting light (see p. 385 and Fig. 10). The fluorescence emitted has therefore to pass through the solution to the detector and during this passage some of it is re-absorbed by other molecules of the compound under examination. The higher the concentration of the compound, the greater is the proportion of the emitted fluorescence reabsorbed. Therefore, linearity between fluorescence intensity and concentration can only be expected at high dilutions where the number of molecules present is small enough to make the extent of re-absorption unimportant compared with the amount of fluorescence emitted. However, the effect of concentration is dependent to some extent upon instrumental factors such as slit widths, intensity of the exciting light, and whether the instrument is one of the common type which detects fluorescence at right angles to the exciting light or one of the more specialized instruments which detects fluorescence at the same face as that being excited. Slit-width and light intensity should be kept constant during any fluorimetric assay. The

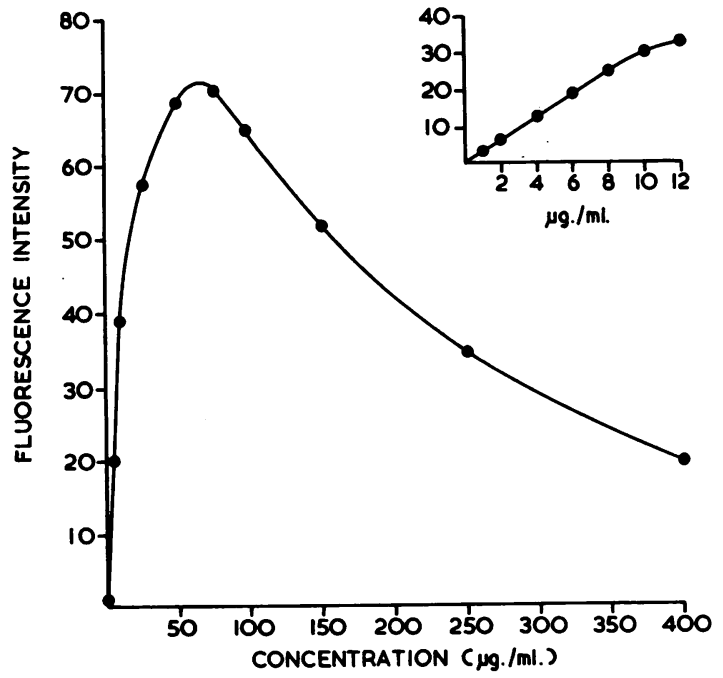

FIG. 3. Concentration quenching of the fluorescence of phenol in water. The large graph covers the concentration range 0-400 $\mu \mathrm{g} . / \mathrm{ml}$., the inset $0-12 \mu \mathrm{g} . / \mathrm{ml}$. (excitation,

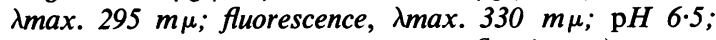
temp. $22^{\circ}$ C.; Aminco-Bowman spectrofluorimeter).

following approximate concentration ranges in $\mu \mathrm{g} . / \mathrm{ml}$. over which fluorescence is proportional to concentration have been found by us for certain compounds, using an Aminco-Bowman spectrofluorimeter:-phenol, $0.01-8 \cdot 0 ;$ sulphanilamide, 0.05-5.0; salicylic acid, 0.01-2.0; aniline, 0.01-6.0; pyridoxine, $0.02-5 \cdot 0$; and 3-hydroxypyridine, $0 \cdot 25-$ 5.0 (Bridges and Williams, 1963). These ranges, of course, depend upon the inherent fluorescence intensity of the compound, for a compound with a weak fluorescence could be expected to show a linear fluorescence intensity/concentration range at a higher concentration than an intensely fluorescent compound. Figure 3 shows the effect of concentration on the fluorescence intensity of phenol. This is a typical example of the effect of concentration.

EFFECT OF SOLVENT Intensity and wavelength of fluorescence can be affected by change of solvent but the effect is often unpredictable. In discussing the solvent effect it will be convenient to consider three aspects, namely, purity of the solvent, nonaqueous solvents, and aqueous solvents.

Since fluorescence is a highly sensitive technique it is important that the solvents used should themselves be non-fluorescent and free from fluorescent impurities. These solvents may be used either for extracting the desired material or for the actual fluorescence measurement. Apart from water, 
solvents used in fluorescence work may include the simple alcohols from methanol to butanol, ether, benzene, ethylene dichloride, hexane, heptane, etc. All solvents should be checked that they do not contain any undesirable fluorescence, and otherwise rigorously purified. Details of the purification of solvents can be obtained from standard texts (e.g., Udenfriend, 1962). There are other sources of fluorescent impurities apart from solvents and particular attention should be paid to detergents used to clean glassware. These detergents may themselves be fluorescent. On the other hand, there are some cleansing agents which quench fluorescence and these should be avoided or carefully removed. Chromic acid, for example, absorbs ultraviolet light (see p. 383) and it is preferable to clean cuvettes in nitric acid rather than in chromic acid. Some solvents also absorb specific wavelengths of light e.g., benzene, and should be avoided for fluorescence involving the regions of their absorption. Apart from solvents, the preparation of solutions for fluorescence assay often involves materials such as adsorbents, e.g., alumina and buffer chemicals, and obviously the possibility of the addition of fluorescent impurities or quenching agents from these materials to the solution to be assayed must be borne in mind.

Non-aqueous solvents are not frequently used as media for fluorescent substances in biological work, but there is no reason why they should not be used. Fluorescence often varies with solvent and several reasons have been put forward to explain this (Van Duuren, 1963), such as the dielectric constant of the solvent, the association of solvent and solute by hydrogen bonding, quenching by solvent molecules, and ionization. Indole, for example, shows the same maximum excitation of $285 \mathrm{~m} \mu$ in five solvents, but the wavelength of maximum fluorescence is 297 in cyclohexane, 305 in benzene, 310 in dioxan, 330 in ethanol, and $350 \mathrm{~m} \mu$ in water. The fluorescence wavelength thus increases with the dielectric constant of the solvent, due to an effect on the $\pi$-electrons. At $5 \mu \mathrm{g}$. $/ \mathrm{ml}$., indole-3-acetic acid is not fluorescent in cyclohexane or benzene, but fluoresces at 325 in dioxan, 340 in ethanol, and $360 \mathrm{~m} \mu$ in water. Chlorophyll shows very little fluorescence in rigorously dried non-polar solvents, but the addition of a polar solvent (methanol, ethanol, or water) causes a remarkable enhancement of fluorescence probably due to hydrogen bonding between chlorophyll and the polar solvent (Livingston, Watson, and McArdle, 1949). Pyridoxine fluoresces at $335 \mathrm{~m} \mu$ in dioxan and $400 \mathrm{~m} \mu$ in water and this change is due to ionization. In dioxan, pyridoxine occurs in the uncharged form whilst in water as the dipolar ion (Bridges et al., 1963):-

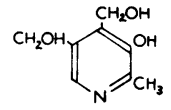

Pyridoxine (molecular). Exc. 296 $m \mu$; flu: $335 m \mu$ in dioxan

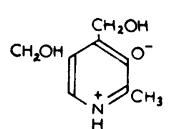

Pyridoxine (dipolar ion). Exc. $332 \mathrm{m \mu}$; flu: $400 \mathrm{m \mu}$ in water

Another interesting example of ionization is $\stackrel{\mathbb{D}}{2}$ 2-hydroxybiphenyl which fluoresces at $348 \mathrm{~m} \mu$ in के ethanol and at $415 \mathrm{~m} \mu$ in water although the $\vec{\circ}$ excitation $(295 \mathrm{~m} \mu)$ is the same in both solvents (Bridges, Creaven, Davies, and Williams, 1963). In this case, the difference in fluorescent wavelengths is due to excited state ionization in water ? but not in ethanol (see p. 380).

A good illustration of the effect of solvent upon fluorescence is shown in Table III, where the intensity of fluorescence of solutions of sulphanilamide $(2 \mu \mathrm{g} . / \mathrm{ml}$.) in various solvents is shown. It will be noted that sulphanilamide does not fluoresce in two ketones, in two highly chlorinated methanes, in the nitro compound, nitromethane, and $p$-xylene. The fluorescence of sulphanilamide is most intense in the lower alcohols and least in the aromatic hydrocarbons (Bridges, 1963).

TABLE III

INTENSITY OF FLUORESCENCE OF SULPHANILAMIDE IN VARIOUS SOLVENTS ${ }^{1}$ (BRIDGES, 1963)

\begin{tabular}{lclc} 
Solvent & $\begin{array}{c}\text { Relative } \\
\text { Intensity }\end{array}$ & Solvent & $\begin{array}{c}\text { Relative } \\
\text { Intensity }\end{array}$ \\
\hline Water & 100 & 1,2-Dichloroethane & 69 \\
Methanol & 72 & n-Hexane & 42 \\
Ethanol & 107 & Benzene & 17 \\
Propanol & 89 & Toluene & 9 \\
Isopropanol & 94 & p-Xylene & 0 \\
n-Butanol & 69 & Light petroleum & 24 \\
& & (b.p. 60-80 $)$ & 78 \\
Isobutanol & 7 & Ether & 33 \\
n-Pentanol & 48 & Ethyl acetate & 70 \\
Acetone & 0 & Formamide & 44 \\
Butan-2-one & 0 & Dimethylformamide & 24 \\
Chloroform & 0 & Dioxan & 0 \\
Carbon tetrachloride & 0 & Nitromethane &
\end{tabular}

${ }^{1}$ Measured in an Aminco-Bowman spectrofluorimeter. The excitation wavelengths varied slightly with the solvent from $270 \mathrm{~m} u$ in iso- $\mathrm{N}$ butanol to $305 \mathrm{~m} \mu$ in toluene. The fluorescence occurred at $350 \mathrm{~m} \mu$ の in every case. The fluorescence intensity in water is taken as 100 .

Concentration of sulphanilamide, $2 \mu \mathrm{g} . / \mathrm{ml}$.

RAMAN SPECTRA OF SOLVENTS When very small amounts of a fluorescent substance in solution have to be measured, there is the possibility that the $\frac{\mathrm{C}}{\mathbb{D}}$ measurement may be interfered with by the so-called $\stackrel{\oplus}{+}$ Raman scattering of the solvent. When this occurs 0 it is advisable to change the solvent. Raman $\bar{O}$ scattering is a phenomenon which is common to gases, liquids, and solids, for when monochro- $\overrightarrow{\mathbb{D}}$ matic light falls on a substance, some of it is $\frac{2}{\sigma}$ scattered by the molecules of that substance. If the spectrum of the scattered light, which is called ao 
Raman spectrum, is examined, it is found to contain wavelengths of light which are characteristic of the substance illuminated and there is a constant relationship between the wavelengths of the Raman lines and the wavelength of the incident light. In fact, Raman spectra are useful in determining molecular structure (Cleveland, 1955). However, Raman spectra, unlike fluorescence spectra, have no absolute excitation and emission wavelengths and can arise from any wavelength of incident light. If a Raman line of the solvent happens to coincide with the fluorescence maximum of the compound being estimated, it could interfere considerably with the estimation and the solvent should be changed. However, Raman scattering is usually weak and may interfere only at high dilutions of the fluorescent substance. According to Parker (1959), the Raman spectrum of a solvent can provide a most useful means of checking the day-to-day sensitivity of a spectrofluorimeter.

BUFFERS In biological work, fluorescence is frequently measured in aqueous buffer solutions. It is therefore important to know whether the constituents of the buffer affect the fluorescence. Table IV shows the effect of various buffers upon the fluorescence of sulphanilamide at $2 \mu \mathrm{g}$. $/ \mathrm{ml}$. and it can be seen that buffers containing $0 \cdot 1 \mathrm{M}$ phosphate, borate, citrate, and phthalate and $0.05 M$ tris(hydroxymethyl)aminomethane (Tris) have an effect on fluorescence intensity although not a very marked one (Bridges, 1963). It has been reported by Cowgill (1963) that $0.05 M$ Tris buffer $(p \mathrm{H} \mathrm{7.5)}$ had no quenching effect upon the fluorescence of indole or phenol. Phosphate, however, quenched both indole and phenol fluorescence, and in the quenching of phenol, the di-anion, $\mathrm{HPO}_{4}^{2-}$, was more effective

\section{TABLE IV}

EFFECT OF BUFFER COMPOSITION ON THE FLUORESCENCE OF SULPHANILAMIDE ${ }^{1}$ (BRIDGES, 1963)

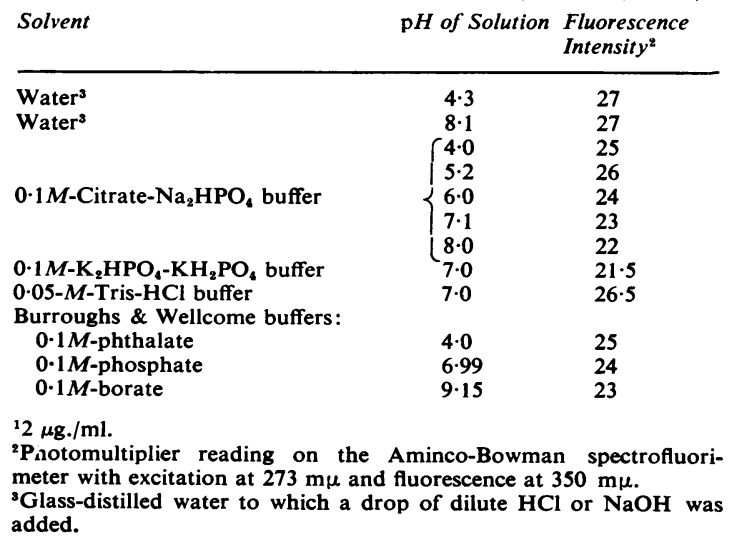

than the mono-anion, $\mathrm{H}_{2} \mathrm{PO}_{4}^{-}$, whilst in the quenching of indole the mono-anion was more effective than the di-anion. Both acetic acid and sodium acetate are weak quenchers of tyrosine fluorescence but, in the case of the fluorescence of tryptophan, acetic acid but not sodium acetate is a quencher. Commercial buffer solutions contain constituents which are not always disclosed by the manufacturers. These constituents could have a fluorescence of their own or they could be quenching agents. Buffers therefore should always be checked for their effects on fluorescence. In the case of phosphate buffers, an increase of phosphate concentration frequently leads to a diminution in fluorescence intensity.

$p$ H EFFECTS Many biologically important compounds are capable of undergoing ionization and the ionic forms of a compound often have different fluorescence characteristics from the unionized form. The effect of $p \mathrm{H}$ upon the fluorescence of a compound is thus of considerable importance, and a knowledge of the changes in fluorescence brought about by $p \mathrm{H}$ changes in the medium can be valuable from several aspects. Thus a compound may be fluorescent only over a short range of $p \mathrm{H}$, as in the case of sulphapyridine, which is practically nonfluorescent above $p \mathrm{H} 4$ and is maximally fluorescent at $p \mathrm{H} 0.5$ to 1.0 (Bridges, 1963). Again, a compound may be fluorescent over a considerable range of $p \mathrm{H}$, but over a certain section of that range it may be much more fluorescent than over the rest. Thus salicylic acid shows some fluorescence from $p \mathrm{H}$ 0 to 14 , but over the range $p \mathrm{H} 4$ to 12 , it is 100 times as fluorescent as at $p \mathrm{H} 1$ (Rosen and Williams, 1961). $p \mathrm{H}$ can also be used to distinguish compounds of similar structure as in the case of tryptamine and 5-hydroxytryptamine (5HT). At $p \mathrm{H} 2$ to 10 , both these compounds fluoresce at about 350 to $360 \mathrm{~m} \mu$, but at $p \mathrm{H}$ approximately -0.5 (about $3 N$ acid) 5-hydroxytryptamine fluoresces at $540 \mathrm{~m} \mu$, whereas tryptamine is non-fluorescent (Bridges and Williams, 1963).

$p \mathrm{H}$-Fluorescence changes are also the basis of the so-called fluorescent indicators. In this case the fluorescence is usually visible, and the appearance of visible fluorescence is useful as an indicator in the titration of cloudy or coloured solutions where normal indicators, which show $p \mathrm{H}$ changes by alteration in colour, are of little use. A good example of such an indicator is 2-naphthol which, when viewed under ultraviolet light, changes from colourless to blue at $p \mathrm{H} \mathrm{6-8.} \mathrm{At} \mathrm{low} p \mathrm{H}$ values, 2-naphthol emits the invisible ultraviolet fluorescence of unionized naphthol, but above $p \mathrm{H}$ 6-8 it emits the blue fluorescence of the naphtholate anion. 
$p \mathrm{H}-\mathrm{Fluorescence} \mathrm{changes} \mathrm{can} \mathrm{also} \mathrm{be} \mathrm{used} \mathrm{for} \mathrm{the}$ determination of the approximate $\mathrm{pKa}$ of acids and bases in minute amounts. These can be determined from $p \mathrm{H} /$ intensity curves and sometimes from $p \mathrm{H} /$ excitation or fluorescence wavelength diagrams, provided that there is a gradual change in wavelength from unionized to ionized forms.

The points mentioned above in this section can best be illustrated by actual $p \mathrm{H}$-fluorescence curves. Figure 4 shows the $p \mathrm{H}$-fluorescence intensity curve

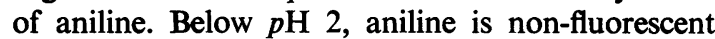
and at this $p \mathrm{H}$ it occurs as the anilinium cation. Above $p \mathrm{H} \mathrm{2,} \mathrm{the} \mathrm{fluorescence} \mathrm{intensity} \mathrm{rises} \mathrm{and} \mathrm{the}$ curve follows exactly the ionization curve of the cation to molecular aniline (pKa 4.5). At about $p \mathrm{H} 7.5$ to 8.0 the intensity reaches a maximum and remains constant to about $p \mathrm{H} 11$ to 12 and then falls to a small value at higher $p H s$. The constant intensity is due to molecular aniline, but the fall at about $p \mathrm{H} 12$ may be due to the formation of an aniline anion. The formation of this anion is suggested by the fact that monomethylaniline, which has a replaceable hydrogen atom, behaves exactly like aniline, but dimethylaniline, which does not have such a hydrogen, does not lose its fluorescence at high $p \mathrm{H}$ values (Williams, 1959). Indole also loses its characteristic fluorescence at high $p \mathrm{H}$ values (e.g., $5 N-\mathrm{NaOH})$ for a similar reason, but $N$ methylindole is still fluorescent at these $p \mathrm{H}$ values since it has no replaceable hydrogen (White, 1959).

Figure 5 shows the $p \mathrm{H} /$ intensity curves for indole, dimethyltryptamine, and 5-hydroxydimethyltryptamine. Between $p \mathrm{H} 3$ and 11, these three compounds fluoresce in the same region of 340 to

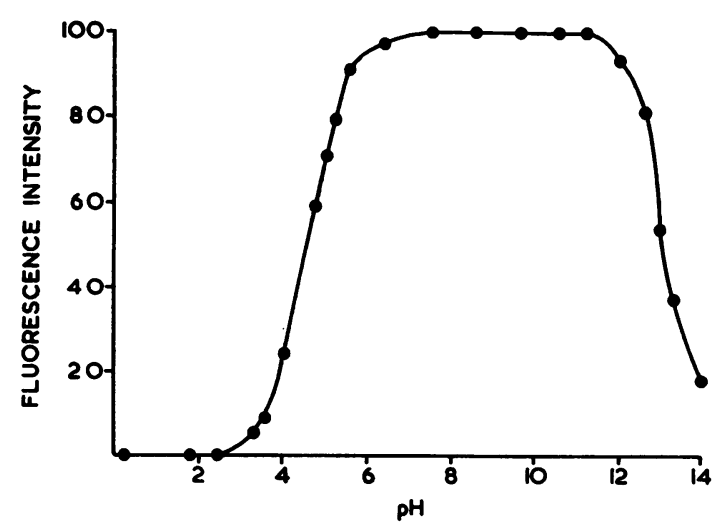

FIG. 4. The effect of $\mathrm{pH}$ upon the fluorescence intensity of aniline in aqueous solution (concentration $5 \mu \mathrm{g} . / \mathrm{ml}$.). (The pKa of aniline is 4.5 and the ionization fits the fluorescence intensity curve exactly; excitation, $\lambda$ max. $290 \mathrm{m \mu}$; fluorescence, $\lambda$ max. $348 \mathrm{m \mu}$; Aminco-Bowman spectrofluorimeter.)

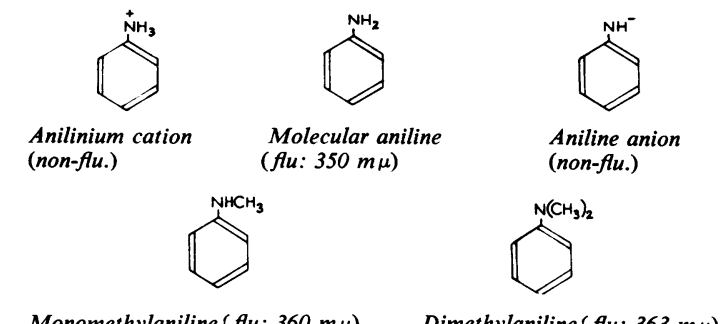

Monomethylaniline ( $\mathrm{fu}: 360 \mathrm{m \mu}$ )

Dimethylaniline ( $f u$ : $363 \mathrm{m \mu}$ )

$360 \mathrm{~m} \mu$. However, at low $p \mathrm{H}$ values, i.e., from $\overrightarrow{\vec{\omega}}$ $p \mathrm{H}-1$ to 1 , 5-hydroxytryptamine alone shows a? fluorescence at $540 \mathrm{~m} \mu$, whereas at high $p \mathrm{H}$ values,? i.e., 14 to 15 ( $N$ to $10 N-\mathrm{NaOH})$, only dimethyl- $\vec{V}$ tryptamine shows any appreciable fluorescence and this occurs at $415 \mathrm{~m} \mu$ (see Table V). Figure 6 shows $\stackrel{\omega}{-}$ the $p \mathrm{H} /$ intensity curve for 5-hydroxyindole-3-acetic acid. This compound (see Table V) shows the typical indole fluorescence between $p \mathrm{H}-0.2$ to $13, \vec{c}$ but in strong acid it shows a fluorescence at $545 \mathrm{~m} \mu \stackrel{\bigodot}{=}$ characteristic of 5-hydroxyindoles and in halfnormal and normal alkali it shows a fluorescence at $\mathscr{O}$ $455 \mathrm{~m} \mu$. In strong alkali $(5-10 N)$ it is non-fluorescent ${ }^{+}$ (Bridges and Williams, 1963).

EXCITED STATE IONIZATION The fluorescence of a⿳亠二口犬 compound capable of ionizing depends upon the $p \mathrm{H}$ of the solution, for the fluorescence of the $\mathbb{Q}$ ionic form is frequently different from that of the $\vec{\circ}$

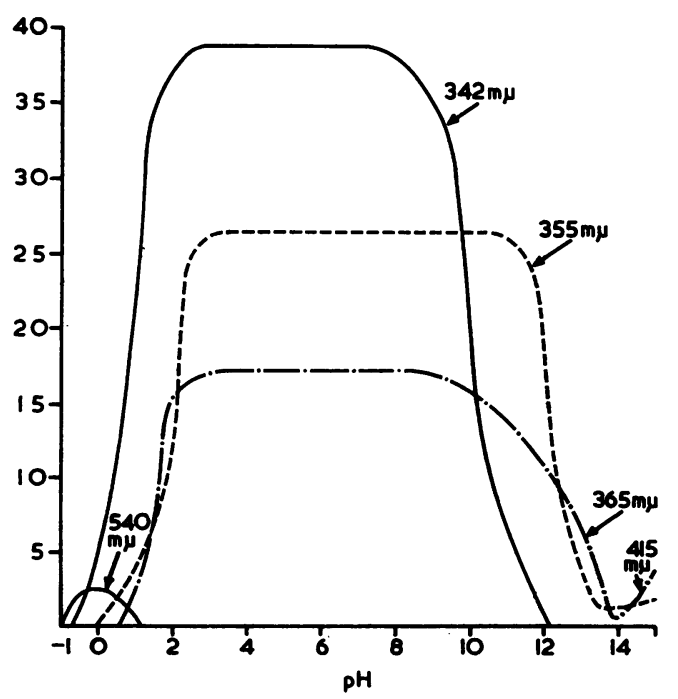

FIG. 5. The effect of $\mathrm{pH}$ upon the fluorescence intensity of indole (-- - -), dimethyltryptamine (--.-), and 5-hydroxydimethyltryptamine or bufotenine (-). Concentration in each case, $1 \mathrm{\mu g} . / \mathrm{ml}$. (Aminco-Bowman spectrofluorimeter.) 
TABLE V

FLUORESCENCE OF SOME INDOLES ${ }^{1}$

(BRIDGES AND WILLIAMS, 1963)

\begin{tabular}{|c|c|c|c|}
\hline Compound & $\begin{array}{l}\text { Excitation } \\
(m \mu)\end{array}$ & $\begin{array}{l}\text { Fluorescence } \\
(m \mu)\end{array}$ & pH Range \\
\hline Indole & $\left\{\begin{array}{l}\overline{285} \\
285\end{array}\right.$ & $\begin{array}{l}\text { None } \\
355 \\
355-400 \\
\text { (weak) }\end{array}$ & $\begin{array}{c}-1 \text { to } 0 \\
0 \text { to } 13 \cdot 7 \\
14 \text { to } 15\end{array}$ \\
\hline Dimethyltryptamine & $\left\{\begin{array}{l}\overline{290} \\
295 \\
300\end{array}\right.$ & $\begin{array}{l}\text { None } \\
365 \\
415 \\
358\end{array}$ & $\begin{array}{l}-1 \text { to } 0 \\
0.4 \text { to } 13.0 \\
14.0 \text { to } 14.7 \\
15\end{array}$ \\
\hline $\begin{array}{l}\text { 5-Hydroxydimethyl- } \\
\text { tryptamine }\end{array}$ & $\left\{\begin{array}{l}304 \\
304 \\
-\end{array}\right.$ & $\begin{array}{l}540 \\
342 \\
\text { None } \\
545\end{array}$ & $\begin{array}{l}-0.7 \text { to } 1.4 \\
-0.3 \text { to } 12 \\
12.5 \text { to } 15 \\
-1.0 \text { to } 1.0\end{array}$ \\
\hline $\begin{array}{l}\text { 5-Hydroxyindole-3- } \\
\text { acetic acid }\end{array}$ & $\left\{\begin{array}{l}300 \\
300-305 \\
362 \\
-\end{array}\right.$ & $\begin{array}{l}545 \\
340-350 \\
455 \\
\text { None }\end{array}$ & $\begin{array}{l}-1.0 \text { to } 1.0 \\
-0.2 \text { to } 13.0 \\
13.4 \text { to } 14.0 \\
14.4 \text { to } 15\end{array}$ \\
\hline
\end{tabular}

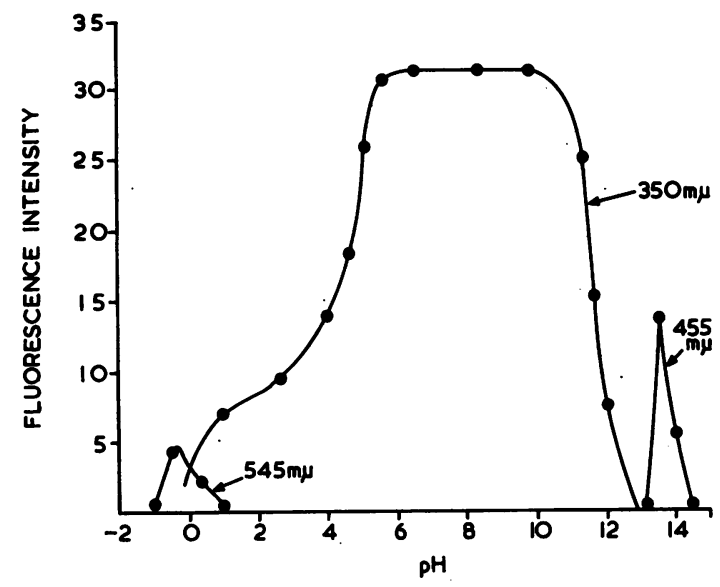

FIG. 6. The effect of $\mathrm{pH}$ upon the fluorescence intensity of 5-hydroxyindole-3-acetic acid (1 $\mu \mathrm{g} . / \mathrm{ml}$.). The scale for the $545 \mathrm{~m} \mu$ fluorescence has been multiplied by 3 (AmincoBowman spectrofluorimeter.)

non-ionized or molecular form. The process of excitation and fluorescence of a compound $\mathrm{MH}$, which is capable of ionizing, can be represented as follows:

$\mathrm{MH}+\mathrm{h}_{\nu_{1}} \stackrel{\text { excitation }}{\longrightarrow} \stackrel{*}{\longrightarrow} \mathrm{H} \stackrel{\text { emission }}{\longrightarrow} \mathrm{MH}+\mathrm{h}_{\nu_{2}}$ where $\nu_{1}$ is the frequency of the exciting light, $\nu_{2}$ the frequency of the fluorescence emitted by MH, h is Planck's constant, and the asterisk indicates the excited state.

For the ion $\mathrm{M}^{-}$, the process is:

$\mathbf{M}^{-}+\mathrm{h}_{\nu_{3}} \stackrel{\text { excitation }}{\longrightarrow} \stackrel{*}{\stackrel{*}{\mathbf{M}}} \stackrel{\text { emission }}{\longrightarrow} \mathbf{M}^{-}+\mathrm{h}_{\nu_{4}}$ where $\nu_{3}$ and $\nu_{4}$ are the frequencies of the excitation and fluorescence, respectively, of the ion.
Some compounds, however, when excited, undergo ionization, so that excitation of the unionized form gives rise to fluorescence corresponding to the ionized form. The compound has thus undergone excited state ionization and the process can be represented as follows:-

$$
\begin{aligned}
& \mathrm{MH}+\mathrm{h}_{\nu_{1}} \stackrel{\text { excitation }}{\longrightarrow} \stackrel{*}{\mathrm{M}} \mathrm{H} \stackrel{\text { ionization }}{\longrightarrow} \stackrel{*}{\mathbf{M}^{-}+\mathrm{H}^{+}} \\
& \mathrm{MH} \leftarrow \stackrel{+\mathrm{H}^{+}}{\longleftarrow} \mathrm{M}^{-}+\mathrm{h}_{\nu_{4}}
\end{aligned}
$$

In practice, this means that some compounds when excited yield the fluorescence of the corresponding ion at $p \mathrm{H}$ values at which, under normal circumstances, the ion does not exist. In fact, the excited molecule has become a much stronger acid than the unexcited or ground molecule. This phenomenon also occurs with bases and the excited base becomes much weaker than the unexcited base. Several examples of this phenomenon are known and it is probably more widespread than hitherto suspected. In our laboratory we have been able to use this phenomenon to estimate fluorimetrically the two isomers, 2- and 4-hydroxybiphenyl, produced enzymically from biphenyl by liver microsomes. 4-Hydroxybiphenyl (pKa 9.5) fluoresces at $340 \mathrm{~m} \mu$ (excitation, $288 \mathrm{~m} \mu$ ) from $p \mathrm{H}-1.0$ to $9 \cdot 2$, and at $401 \mathrm{~m} \mu$ (excitation, $311 \mathrm{~m} \mu$ ) from $p \mathrm{H} 10$ to 14 . The change of fluorescence with $p \mathrm{H}$ is what would be expected, since the change occurs at $p \mathrm{H} 9$ to 10 where 4-hydroxybiphenyl undergoes ionization. With 2-hydroxybiphenyl (pKa 10.0), however, the fluorescence changes at $p \mathrm{H} 1$ whereas the excitation changes at $p \mathrm{H} 9.5$ to 10.5 . From $p \mathrm{H}-1$ to 1 , 2-hydroxybiphenyl fluoresces at $348 \mathrm{~m} \mu$ (excitation, $295 \mathrm{~m} \mu$ ); from $p \mathrm{H} 1$ to 9.5 it fluoresces at $415 \mathrm{~m} \mu$ (excitation, $295 \mathrm{~m} \mu$ ); and from $p \mathrm{H} 9.5$ to 14 it fluoresces at $415 \mathrm{~m} \mu$ but the excitation is now at $320 \mathrm{~m} \mu$. These changes are shown in Figure 7 . From the fluorescence changes it can be calculated that the pKa of excited 2-hydroxybiphenyl is about $1 \cdot 5$, so that in the excited state it is a hundred million times stronger as an acid than in the unexcited state. It can be seen that at $p \mathrm{H} 6$, the 4-isomer fluoresces at $340 \mathrm{~m} \mu$ whereas the 2isomer fluoresces at $415 \mathrm{~m} \mu$ and therefore one can be estimated in the presence of the other.

We have found several compounds to exhibit this phenomenon and a list is given in Table VI. The effect of $p \mathrm{H}$ is further discussed in the section on fluorescent molecules of biological interest.

TEMPERATURE Fluorescence intensity tends to in- 


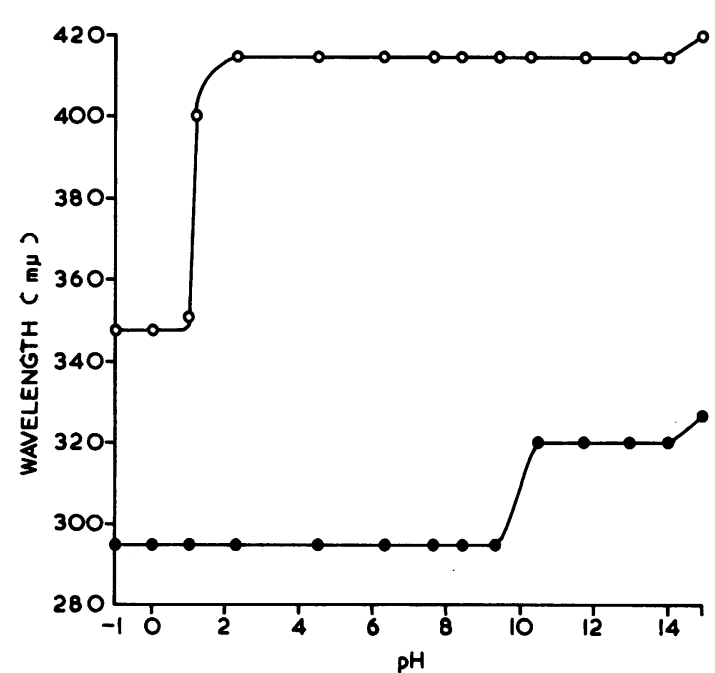

FIG. 7. The effect of $\mathrm{pH}$ upon the maximum excitation and fluorescence wavelengths of 2-hydroxybiphenyl (4.2 $\mu \mathrm{g} . / \mathrm{ml}$.) - excitation, $\bigcirc-\bigcirc$ fluorescence. The pKa of 2-hydroxybiphenyl is 10.0; the excited pKa is about 1.5 (Aminco-Bowman spectrofluorimeter.)

\section{TABLE VI}

SOME COMPOUNDS SHOWING EXCITED STATE IONIZATION

\author{
2-Hydroxybiphenyl \\ 3-Hydroxypyridine \\ Pyridoxine \\ Pyridoxal \\ Pyridoxal phosphate \\ Pyíidoxamine
}

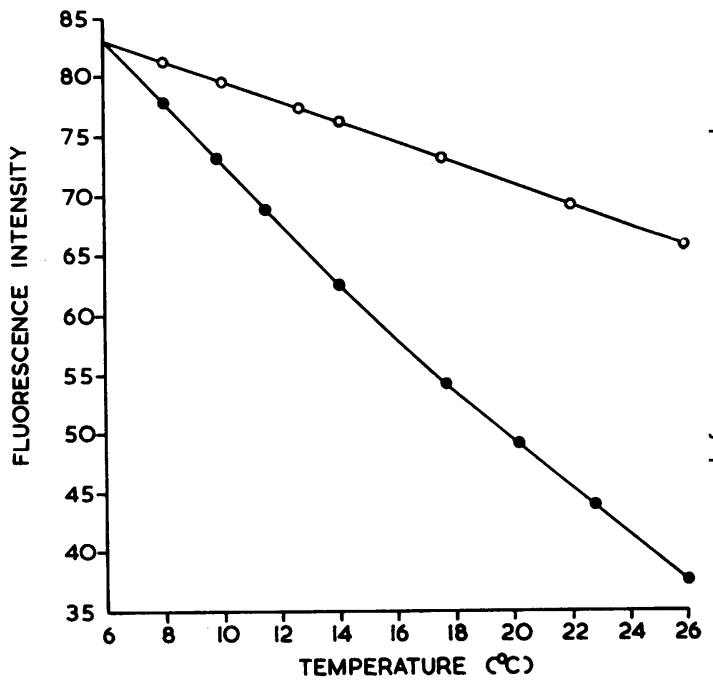

FIG. 8. The effect of temperature on the fluorescence intensity of phenol $(\bigcirc-\bigcirc)$ at $2 \mu \mathrm{g} . / \mathrm{ml}$. and $\mathrm{pH} 6.8$ (fluorescence $\lambda$ max. $330 \mathrm{m \mu}$ ) and of p-anisidine (-O) at $2 \mu \mathrm{g} . / \mathrm{ml}$. and $\mathrm{pH} 9.5$ (fluorescence $\lambda \max .350 \mathrm{m \mu}$ ). (Aminco-Bowman spectrofluorimeter.)

change of fluorescence intensity of $5 \%$ per degree. These include aqueous solutions of indole-3-acetic $\stackrel{\otimes}{\mathbb{D}}$ acid, tryptophan (Udenfriend, 1962), p-anisidine, and $p$-toluidine (Bridges and Williams, 1962). In $\overline{0}$ these instances some form of temperature control would be desirable. Examples of temperature changes in fluorescence are shown in Figure 8. (Temperature control of the cell compartment has very recently용 become available for the Aminco-Bowman, Farrand and Zeiss spectrofluorimeters.)

crease to a maximum with fall in temperature and to decrease to zero at high temperatures. The effect of temperature upon fluorescence is not fully understood but one can assume that it is connected with the movement of molecules in the medium. When the temperature rises, the motion of the molecules increases and there is a greater tendency for collisions. This would result in the loss of some of the energy which might have been radiated as fluorescence. For most practical purposes temperature changes within a few degrees are unimportant, but one must be aware of them because there are some compounds whose fluorescence intensity is particularly sensitive to temperature changes. Most fluorimeters have no means of controlling the temperature of the cell compartment, which can change several degrees as a result of the heat emitted by the light source. With most compounds a change of $1^{\circ} \mathrm{C}$. may cause an intensity change of about $1 \%$. However, compounds are known which exhibit a

PHOTO-DECOMPOSITION The stability of a compound when it is irradiated by ultraviolet light is an 을 important consideration in fluorimetry. Most $>$ fluorescence assays are carried out on highly dilute solutions and there are several fluorescent com- $\bar{N}$ pounds which photo-decompose in dilute solutions although they may be more stable in more con- $N$ centrated but still dilute solutions. Thus highly $\underset{\omega}{N}$ dilute solutions of quinine bisulphate $(0.01 \mu \mathrm{g} . / \mathrm{ml}$.) are unstable in ultraviolet light whilst more con- 0

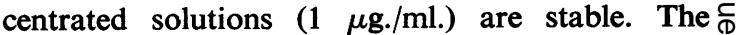
extent of photo-decomposition depends upon the? intensity of the light source, and, whilst a very 0 intense light source may greatly enhance the

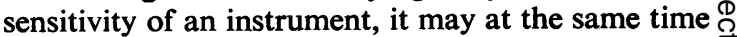
cause increased photo-decomposition. However, $\stackrel{\mathbb{Q}}{\mathbb{Q}}$ even though photo-decomposition does occur, $\bar{O}$ rapid measurements can be carried out before much of the compound is decomposed. Thus we 


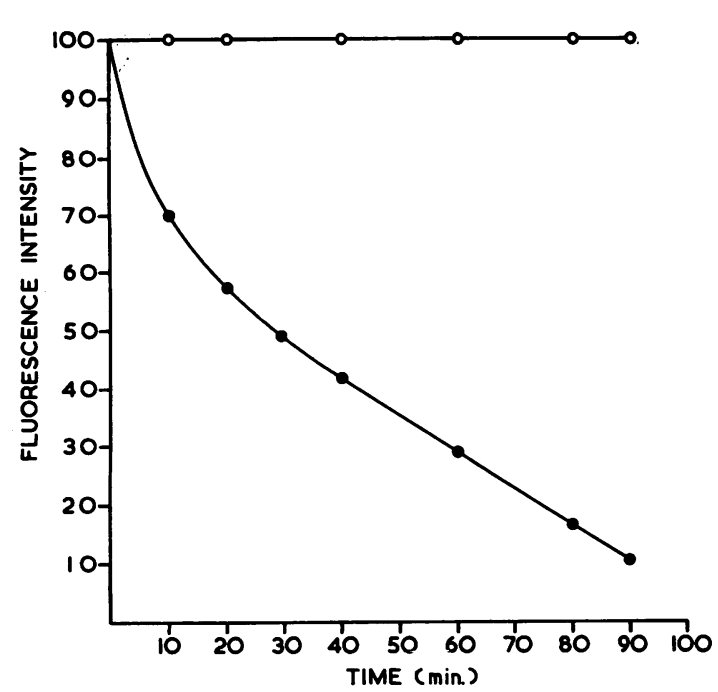

FIG. 9. The effect of ultraviolet light $(295 \mathrm{m \mu})$ on the fluorescence intensity of 3-pyridol at $5 \mu \mathrm{g} . / \mathrm{ml}$. and $\mathrm{pH} 6.5$ $(\mathrm{O}-\mathrm{O})$ and of pyridoxine at $5 \mu \mathrm{g} . / \mathrm{ml}$. and $\mathrm{pH} 6.8$ (-). The fluorescence $\lambda$ max. was $400 \mathrm{~m} \mu$ for both compounds (Aminco-Bowman spectrofluorimeter.)

have found that sulphanilamide $(5 \mu \mathrm{g} . / \mathrm{ml}$.) in water undergoes photo-decomposition when exposed to light of wavelength $275 \mathrm{~m} \mu$ to nonfluorescent products. However, decomposition is only appreciable after 30 seconds and the intensity of fluorescence of sulphanilamide can be measured within this period. It has also been found that pyridoxine, pyridoxal and its $5^{\prime}$-phosphate, and pyridoxamine $(2 \mu \mathrm{g} . / \mathrm{ml}$.) undergo photo-decomposition in ultraviolet light. These compounds are derivatives of 3-hydroxypyridine which itself is stable in light. The rate of photo-decomposition of some of these compounds is shown in Figure 9.

It should be mentioned that photo-decomposition does not always lead to loss of fluorescence and in some cases it leads to the enhancement of production of fluorescence. Thus coumarin, 4-aminoquinolines, and certain flavine derivatives are weakly fluorescent, but on exposure to ultraviolet light of suitable wavelengths, they photo-decompose to highly fluorescent products which may be utilized for their detection and estimation (Feigl, Feigl, and Goldstein, 1955; Brodie, Udenfriend, Dill, and Chenkin, 1947; Kuhn, Wagner-Jauregg, and Kaltschmitt, 1934).

\section{FLUORESCENCE QUENCHING}

When one compound diminishes or abolishes the fluorescence of another, it is said to quench the fluorescence. The quenching of fluorescence can be brought about in many ways and the mechanism of quenching is complicated. Furthermore, the quenching of one compound by another is often unpredictable. In this section, an attempt has been made to reduce the theoretical aspects of quenching to simple terms. On these terms, it can be said that quenching may be brought about in four ways, namely, (1) by absorption by the quencher of the exciting light; (2) by absorption of the fluorescence; (3) by degradation of the energy of the excited molecule so that this energy cannot be emitted as light; and (4) by a chemical change in the fluorescent molecule.

QUENCHING BY INNER FILTER EFFECTS The absorption of the excitation ( 1 above) and the absorption of the fluorescence ( 2 above) by the quencher are known as 'inner filter' effects, and they are not easily distinguishable. In fact, a quencher could do both. Such effects are found with solvents which absorb light of wavelengths close to those of the exciting or fluorescent light. Examples of such solvents are acetone, benzene, and phenol, which absorb in the ultraviolet and are unsuitable for work in this region. It is clear that when such solvents are used for extraction procedures, they must be carefully removed before the final solution is examined fluorimetrically. The quenching effect of acetone, however, has been suggested as the basis of a fluorimetric method for measuring acetone and organic acids which can be decomposed into acetone. The fluorescence of $\beta$-naphthol in aqueous solution is quenched by acetone and the extent of quenching is proportional to the concentration of acetone (Hynie, Večerek, and Wágner, 1960).

Another instance of the inner filter effect is concentration quenching or self-quenching, a point which has already been discussed on page 377 .

Light scattering due to very fine particles can also be regarded as a kind of quenching and this can be avoided by filtration or, if the particles are very fine, by centrifugation at high speed.

The quenching effect of traces of dichromate has already been mentioned (see p. 378) and this effect may be partly due to the absorption of light by dichromate. The dichromate ion has absorption peaks at 275 and $348 \mathrm{~m} \mu$ which overlap, for example, the excitation and fluorescence peaks of tryptophan (Udenfriend, 1962).

QUENCHING BY ENERGY DEGRADATION The degradation of the energy of the excited state by the quencher can occur in several ways, for example, by conversion of the excited molecule into the triplet state, by electron transfer, or by energy transfer. 
These forms of quenching are often known as 'true' quenching.

The quenching molecule may affect the fluorescent molecule in such a way as to convert it from the singlet excited state to the triplet state so that it no longer emits its energy as fluorescence (see p. 372). The quenching effect of oxygen, certain iodo, bromo, and nitro compounds, and probably pyridine may be due to this effect. In the case of the halogen compounds the large magnetic fields of the halogen atoms may be responsible for the conversion. In the case of oxygen, it may be due to the fact that the ground state of the oxygen molecule is a triplet, which, when in contact with the singlet excited state of the molecules of some compounds, exchanges its triplet state for the singlet state of the other molecule:

$$
\mathrm{O}_{2}^{\text {triplet }}+\mathrm{M}^{\text {singlet }} \longrightarrow \mathrm{O}_{2}^{\text {singlet }}+\mathrm{M}^{\text {triplet }}
$$

The quenching effect of oxygen can be avoided by bubbling nitrogen through the solution during the measurement of fluorescence. However, oxygen is not a universal quencher of fluorescence, but it does quench the fluorescence of several aromatic compounds. This observation has been used for the determination of oxygen, employing the fluorescence of a borate-benzoin complex which is quenched by oxygen in proportion to the concentration of the latter (Parker and Barnes, 1957).

The degradation of the energy of the excited molecule can also occur by electron transfer. The excited molecule, but not the corresponding ground molecule, may be able to donate or accept an electron from the quenching molecule and in this way the excited state may be destroyed. Thus ferrous ions destroy the fluorescence of excited methylene blue by electron donation, but have no effect on the unexcited dye. Some fluorescent molecules are quenched by electron-donating anions such as $\mathrm{I}^{-}, \mathrm{Br}^{-}, \mathrm{SCN}^{-}$, and $\mathrm{S}_{2} \mathrm{O}_{3}^{-}$, and others by electronaccepting anions such as $\mathrm{IO}_{3}^{-}, \mathrm{NO}_{3}^{-}$, and $\mathrm{S}_{4} \mathrm{O}_{6}^{-}$, the direction of electron transfer depending upon the redox potential of the excited molecule which is different from that of the unexcited molecule (Bowen and Wokes, 1953). The fluorescence of tryptophan is quenched by thiosulphate or nitrate ions and this effect has been used for identifying tryptophan in tissue fluids (Duggan and Udenfriend. 1956).

For quenching to occur by energy transfer, the energy level of the excited quencher must be just below that of the excited fluorescent molecule. Usually the quencher molecule is one which, on excitation, is converted into the triplet state, so that when the fluorescent molecule is excited, its energy is immediately taken up by the quencher, which then assumes a non-radiative triplet state and the energy absorbed by the fluorescent molecule cannot now has robbed the excited fluorescent molecule of its energy because of the proximity of their energy 0 levels. This type of quenching can readily occur in 흐 solids where the fluorescent and quenching molecules $\frac{\bar{s}}{\frac{\bar{D}}{\sigma}}$ are close together, but it is more difficult to produce $\mathbb{\mathbb { Q }}$ in solution unless high concentrations are used, and then, of course, energy transfer quenching may be difficult to distinguish from concentration quenching. An example of energy transfer quenching is shown by phenazine in solid anthracene. Anthracene has a blue fluorescence, but if it contains one part in a용 thousand of phenazine, the fluorescence is quenched. The energy level of the triplet state of excited phenazine is just below that of the singlet excited state of anthracene (Bowen and Wokes, 1953).

Energy transfer mechanisms are thought to play 윽 an important role in biological systems, particularly those involving proteins (Porter and Weber, 1959; $\subseteq$ Szent-Györgyi, 1957). The fluorescence of NADP is thought to involve an energy transfer mechanism $\vec{\varphi}$ (see p. 389).

QUENCHING BY CHEMICAL CHANGE If a fluorescent compound undergoes a chemical change as a result of the presence of a second compound it could be converted into a non-fluorescent product. Although $\bar{D}$ the fluorescence of the compound is quenched by the addition of the second compound, this form of quenching is to be distinguished from 'true' quenching during which no net chemical change occurs Quenching by chemical change (cf. photo-decomposition, p. 382) can occur in many ways but the end product is usually a non-fluorescent compound. Furthermore this type of quenching can be very specific as the examples given below will show.

Quenching can occur as a result of $p \mathrm{H}$ changes in the solution. A simple case is that of aniline. If acido is added to an aqueous solution of aniline, the $>$ fluorescence begins to be quenched at $p \mathrm{H} 6$, and ato $p \mathrm{H} 2$ the solution is non-fluorescent. This is due ton the conversion of aniline into the non-fluorescent anilinium ion which is a different chemical species $\tilde{O}$ from aniline:-

$$
\begin{array}{ll}
\mathrm{C}_{6} \mathrm{H}_{5} \mathrm{NH}_{2} \longrightarrow & \underset{\mathrm{C}_{6} \mathrm{H}_{5} \stackrel{+}{\mathrm{N}} \mathrm{H}_{3}}{\text { non-fluorescent }} \\
\text { fluorescent } & \text { anilinium ion }
\end{array}
$$

The fluorescence of phenol is quenched when the solution is made alkaline and in this case phenol is converted into the non-fluorescent phenoxide ion.

An example of specific quenching by an acid is that of quinine. In $0 \cdot 1 \mathrm{~N}-\mathrm{H}_{2} \mathrm{SO}_{4}$, quinine $(1 \mu \mathrm{g} \text {./ml. })_{0}^{2}$ is highly fluorescent but in $0 \cdot 1 N-\mathrm{HCl}$, quinine is non-fluorescent (Bowen and Wokes, 1953). Quiningo 
in the excited state probably forms some kind of compound with $\mathrm{HCl}$ which is non-fluorescent.

An extensive study of the quenching effects of purines was made by Weil-Malherbe (1946) who found xanthine, hypoxanthine, caffeine, uric acid, and $N$-methylxanthines to quench the fluorescence of several ccmpounds, probably by forming molecular compounds or complexes. Thus caffeine in acid solution quenches the fluorescence of polycyclic hydrocarbons, whilst in neutral solution it quenches the fluorescence of riboflavin, and intensifies that of thiochrome, mepacrine, and eosin. In the case of tryptophan its fluorescence is quenched by ascorbic acid, the nitrate ion, and the thiosulphate ion, and it is probable that tryptophan is oxidized by these quenchers.

ADSORPTION AND QUENCHING Adsorption of the fluorescent substance on to glassware (including fluorimeter cells) and precipitates, especially protein, frequently occurs in dilute solutions especially with non-polar solvents such as hexane. Such adsorption results in the loss of fluorescent material and consequently in low recoveries. There are many ways in which adsorption can be avoided and these include suitable treatment of new glassware, changing the protein precipitants, changing the solvent, adding a small amount of a polar solvent such as alcohol, etc., but each case has to be dealt with on its merits (see Udenfriend, 1962).

\section{FLUORIMETERS}

A fluorimeter is an instrument used for the measure-

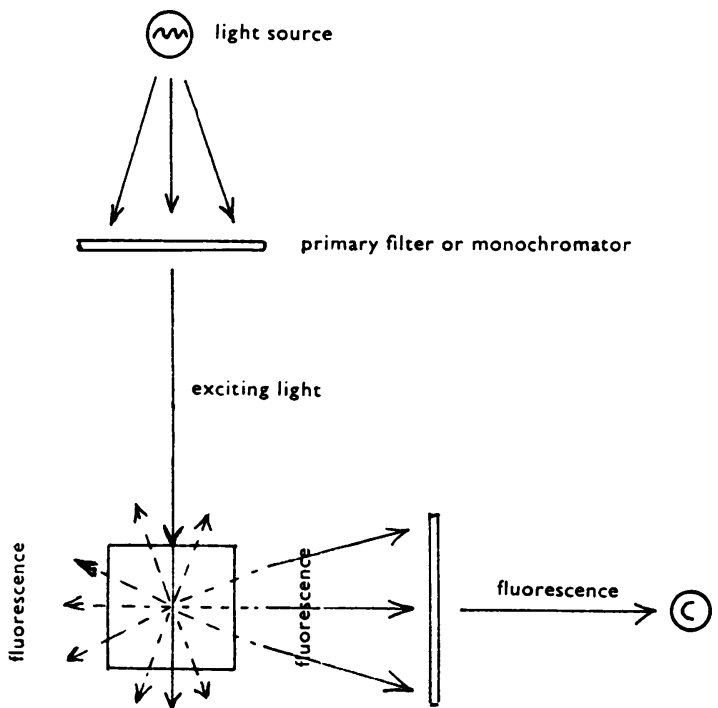

phoco-decector ment of the intensity of fluorescence. If the instrument has means of measuring the wavelength of the fluorescence and of the excitation, it is then called a spectrofluorimeter or more accurately, a fluorescence spectrometer. All fluorimeters, simple or complex, contain three essential units, namely, a source of exciting light, a sample container, usually a cell or cuvette of square section, and a detecting unit for measuring the fluorescence emitted by the sample. To increase the specificity of both the exciting and fluorescent light, most fluorimeters contain two sets of light filters, and the spectrofluorimeters, two monochromators, one to select the exciting light and the other to analyse the fluorescent light. The monochromators are devices consisting of either a diffraction grating or a prism and the necessary slits, lenses, and mirrors, which can be moved mechanically to select a desired wavelength or band of light, which is measured on a wavelength scale or drum attached to the monochromator. A simplified outline of a fluorimeter is shown in Figure 10.

When the exciting light strikes the cuvette fluorescence is emitted from all its faces, but most fluorimeters measure only the fluorescence which is emitted from one face at right angles to the direction of the exciting light. The faces in the direction of the incident light emit fluorescence and exciting light, but even at right angles there is some scattered exciting light to be contended with and this shows up on recording spectrofluorimeters at the wavelength of the exciting light on the fluorescence side of the instrument. In filter instruments, this scattered light can be eliminated to a large degree by suitable secondary filters (see Fig. 10). Filters can also be used in spectrofluorimeters, if scattered light is troublesome as a result of a slight impurity or turbidity in the sample.

LIGHT SOURCES The source of exciting light is an important factor in fluorimeters, and the lamps now in use are the xenon-arc, the high pressure mercury, the tungsten filament, and zinc lamps. Modern spectrofluorimeters utilize the xenon-arc lamp which emits a continuous spectrum from 200 to $800 \mathrm{~m} \mu$. Its brightness in the ultraviolet region is much greater than the tungsten filament lamp and it does not develop line spectra as does the mercury vapour lamp. The mercury lamp gives a discontinuous spectrum consisting of high intensity lines, the

FIG. 10. A simplified outline of a fluorimeter. 
main ones being at $365,405,436$, and $546 \mathrm{~m} \mu$. If a compound is maximally excited in the region of these lines, the mercury lamp is then very suitable for exciting such a compound, but it is less satisfactory for compounds maximally excited at other wavelengths. The fluorimetric estimation of vitamin $B_{1}$ as thiochrome, of adrenaline as adrenolutine or as a quinoxaline derivative, and of riboflavin are excellent examples of compounds whose maximum excitations almost coincide with one of the mercury lines, thus:-

\begin{tabular}{ll} 
Mercury Line & Maximum Excitation for \\
\hline $366 \mathrm{~m} \mu$ & $\begin{array}{l}\text { Thiochrome from vitamin } \mathrm{B}_{1}, 370 \mathrm{~m} \mu \\
405 \mathrm{~m} \mu\end{array}$ \\
$\begin{array}{l}\text { Adrenolutine from adrenaline, } 405 \mathrm{~m} \mu \\
\text { Riboflavin, 440 } \mathrm{m} \mu\end{array}$ \\
$\begin{array}{l}\text { Quinoxaline derivative } \\
\text { from adrenaline, 435 } \mathrm{m} \mu\end{array}$
\end{tabular}

Although the xenon-arc gives a continuous spectrum over the ultraviolet and visible regions its intensity varies with wavelength and tends to

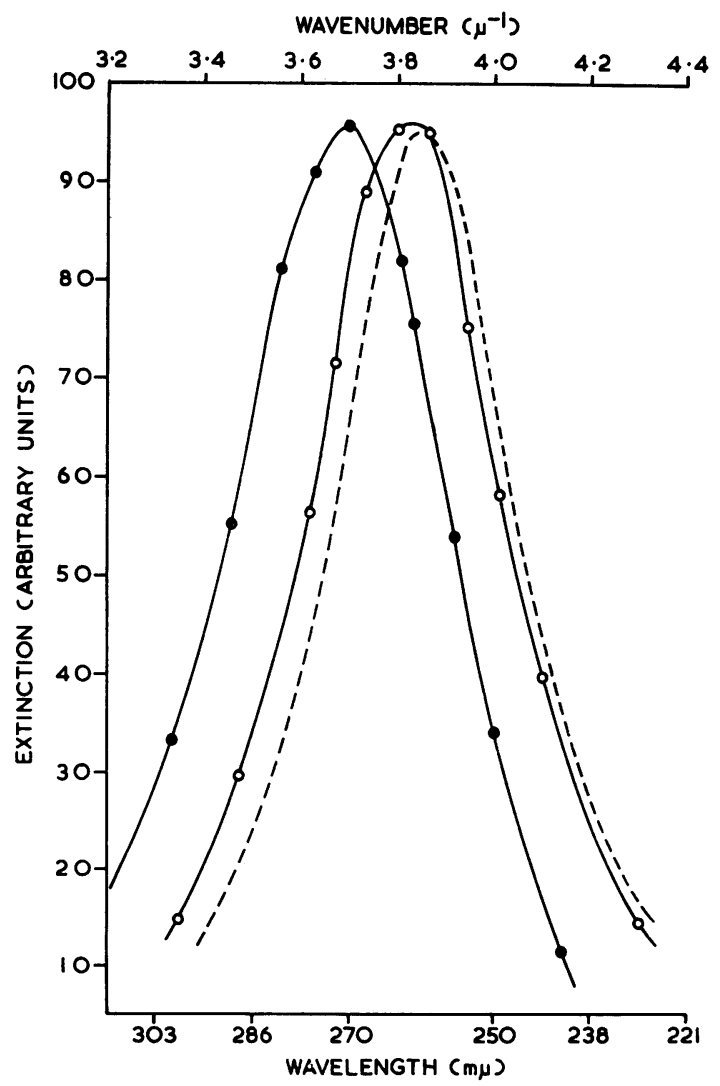

FIG. 11. The absorption spectrum (--.-), uncorrected excitation spectrum (O-O), and corrected excitation spectrum $(\bigcirc-\bigcirc)$ of sulphanilamide at $2 \mu \mathrm{g} . / \mathrm{ml}$. and $\mathrm{pH} 8.4$. The abscissa is given in wavelengths $(m \mu)$ and wave numbers or frequencies (in reciprocal microns, i.e., $\left.\mu^{-1}\right)$. diminish at short wavelengths. This means that $\frac{0}{5}$

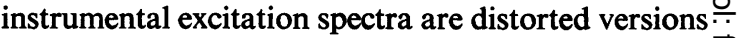
of the true spectra, and instrumental excitation $\overrightarrow{\vec{F}}$ maxima appear at longer wavelengths than the true maxima. For most analytical purposes this is $\frac{C}{0}$ unimportant, but, if necessary, corrections can be $\frac{\bar{\sigma}}{\bar{p}}$ made and the corrected excitation spectra then $\bar{\Phi}$ coincide fairly well with the absorption spectra. An example of this type of correction, which is a tedious process, is shown in Fig. 11 which shows $\vec{O}$ the absorption spectrum, the instrumental and $\vec{\overrightarrow{ }}$ corrected excitation spectra, and the fluorescence ${ }_{\sigma}^{\omega}$ spectrum of sulphanilamide (Bridges, 1963). No light source has yet been obtained which does not? give distorted excitation spectra.

Most filter fluorimeters use the mercury lamp as a light source, since it it easier to isolate the high $\underset{ }{\longrightarrow}$ intensity lines of the mercury spectrum with filterso than any part of the continuous spectrum of the xenon-arc lamp, but intense excitation wavelengthsc from the mercury lamp are limited in number.

CELLS The cells or cuvettes used in fluorimeters are made of glass or silica. If the exciting wavelengths are above $320 \mathrm{~m} \mu$, glass cells can be used, but belowo $320 \mathrm{~m} \mu$ cells of quartz or synthetic silica should be used. It has been found that synthetic silica cellso tend to be more satisfactory than quartz, which is $a \frac{\circ}{\circ}$ natural silica and is more likely to contain impurities $\varrho$ than synthetic silica. All cells should be checked $\overrightarrow{0}$ that they have no fluorescence of their own and 3 rejected if they have (Parker and Rees, 1962).

DETECTORS The detection of fluorescence is now made with photo-multiplier tubes, but the details of these devices will not be discussed except to mention? that with fluorimeters which measure ultravioletio and visible fluorescence two photomultiplier tubes,, one 'ultraviolet sensitive' and one 'visible-sensitive', may be used. Although these phototubes are interchangeable for the greater part of the spectrum, theo ultraviolet-sensitive tube is to be preferred below $330 \mathrm{~m} \mu$, whilst the visible-sensitive tube is mores sensitive at the red end of the spectrum (see RCAN Tube Handbook).

INSTRUMENTS There are two kinds of fluorimeters commercially available, the filter fluorimeters and the spectrofluorimeters, and the main consideration? in deciding which of these instruments to acquire may be an economic one, since the former are much cheaper than the latter. However, spectrofluori $\stackrel{\mathbb{D}}{\circ}$ meters are much more versatile than filter instru依 ments for not only is their range much greater, buf they also allow maximum excitation and fluor escence wavelengths to be determined and excitation 
and fluorescence spectra to be drawn. In fact, they give enough data to the operator to allow analyses to be carried out under optimal conditions. But for many routine analyses, they offer no great advantages over good filter instruments. However, if an institution has a number of filter instruments, a spectrofluorimeter can be very useful in indicating what filters ought to be used for a specific analysis in the filter fluorimeters.

There are several good filter instruments commercially available including those made by the Beckman, Coleman, EEL, Farrand, Hilger-Watt, Locarte, Turner, Photovolt, and Zeiss Instrument companies. Their basic design is similar, a mercury lamp being employed as a light source in most cases. (These instruments generally cost between $£ 200$ and £500.)

The main commercial spectrofluorimeters are the Aminco-Bowman, Farrand, and Zeiss instruments. The first two employ diffraction gratings as monochromators whilst the third, a recently introduced instrument, uses quartz prisms. The use of prisms results in a loss of sensitivity, which is, however, compensated by an increased resolving power, and wavelengths can be determined more accurately. The light sources in all three instruments are xenonarc lamps, the Aminco-Bowman and Farrand instruments employing a 150 watt lamp and the Zeiss instrument a 500 watt lamp whose higher light intensity is intended to compensate for the loss of sensitivity due to the prism optical system. (The basic cost of these instruments is between $£ 1,250$ and $£ 3,000$.)

\section{FLUORESCENT MOLECULES OF BIOLOGICAL INTEREST}

It should now be clear what types of chemical structures are likely to be fluorescent and why simple non-aromatic amino-acids, saturated lipids, steroids (except oestrogens), and carbohydrates are non-fluorescent. There is no reason, however, why it should not be possible to convert the above types of non-fluorescent compounds into fluorescent products by suitable chemical reactions (Udenfriend, 1962). There are a large number of biologically important compounds which contain the necessary conjugated double bond systems and are, therefore, potentially or actually fluorescent. These include aromatic amino-acids, certain proteins, carotinoids, porphyrins, purines, indoles, phenols, oestrogens, vitamins (A, $\mathrm{K}$, pyridoxine, thiamine, riboflavine, tocopherol), hormones (adrenaline, serotonin), and co-enzymes. Furthermore, there are a large number of drugs which are fluorescent e.g., quinine, salicylates, barbiturates, quinoline, antimalarials, cou- marins, tetracyclines, chlorpromazine derivatives, etc. One can usually tell from the structural formula of a compound whether it is likely to be fluorescent, by examining its structure for conjugated double

\section{TABLE VII}

SOME FLUORESCENT NATURAL COMPOUNDS ${ }^{1}$

\begin{tabular}{|c|c|c|c|}
\hline Compound & $\begin{array}{l}\text { Excitation } \\
\text { Maximum } \\
(m \mu)\end{array}$ & $\begin{array}{l}\text { Fluorescence } \\
\text { Maximum } \\
(m \mu)\end{array}$ & $\begin{array}{l}\mathrm{p} H \text { or } \\
\text { Solvent }\end{array}$ \\
\hline Adenosine & 285 & 395 & 1 \\
\hline Adenylic acid & 285 & 395 & 1 \\
\hline Adrenaline & 285 & 325 & 1 \\
\hline p-Aminobenzoic acid & 295 & 345 & 11 \\
\hline Anthranilic acid & 300 & 405 & 7 \\
\hline ATP & 285 & 395 & 1 \\
\hline Folic acid & 365 & 450 & 7 \\
\hline Folinic acid & 370 & 460 & 7 \\
\hline Homogentisic acid & 290 & 340 & 7 \\
\hline Homovanillic acid & 270 & 315 & 7 \\
\hline 5-Hydroxyindolacetic acid & 300 & 355 & 7 \\
\hline Kynurenine & 370 & 490 & 11 \\
\hline NADP. & 340 & 435 & 7 \\
\hline Oestradiol & 285 & 330 & Ethanol \\
\hline Oestrone & 285 & 325 & Ethanol \\
\hline Pyridoxal & 330 & 385 & 7 \\
\hline Pyridoxine & $\begin{array}{l}340 \\
270\end{array}$ & 400 & 7 \\
\hline Riboflavine & $\left.\begin{array}{l}370 \\
445\end{array}\right\}$ & 520 & 7 \\
\hline & $\int 295$ & 340 & 2 \\
\hline Serotonin & 295 & 540 & 0 \\
\hline Tocopherol & 295 & 330 & Ethanol \\
\hline Tryptophan & 285 & 365 & 11 \\
\hline Tryptamine & 290 & 360 & 7 \\
\hline Tyrosine & 275 & 310 & 7 \\
\hline Tyramine & 375 & 310 & 1 \\
\hline Vitamin A & 325 & 470 & Ethanol \\
\hline Vitamin $\mathbf{B}_{12}$ & 275 & 305 & 7 \\
\hline
\end{tabular}

${ }^{1}$ Taken from Duggan, Bowman, Brodie, and Udenfriend (1957); the maxima quoted are instrumental values.

TABLE VIII

SOME FLUORESCENT DRUGS ${ }^{1}$

\begin{tabular}{lllr} 
Compound & $\begin{array}{l}\text { Excitation } \\
\text { Maximum } \\
(m \mu)\end{array}$ & $\begin{array}{l}\text { Fluorescence } \\
\text { Maximum } \\
(m \mu)\end{array}$ & $\begin{array}{c}\mathrm{pH} \text { or } \\
\text { Solvent }\end{array}$ \\
\hline Aminopterin & 280,370 & 460 & 11 \\
Cinchonine & 320 & 420 & 1 \\
Chloroquine & 335 & 400 & 11 \\
Chlorpromazine & 350 & 480 & 11 \\
Dromoran & 275 & 320 & 1 \\
Harmine & 300,365 & 400 & 1 \\
Lysergic acid diethylamide & & & \\
$\quad$ (L.S.D.) & 325 & 465 & 7 \\
Menadione & 335 & 480 & Ethanol \\
Neocinchophen & 275,345 & 455 & 7 \\
Phenylephrine & 270 & 305 & 1 \\
Piperoxane & 290 & 325 & 7 \\
Pamaquin & 300,370 & 530 & 13 \\
Podophyllotoxin & 280 & 325 & 11 \\
Procaine & 275 & 345 & 11 \\
Procainamide & 275 & 385 & 11 \\
Quinine & 250,350 & 450 & 1 \\
Reserpine & 300 & 375 & 1 \\
Oxytetracycline & 390 & 520 & 11 \\
Yohimbine & 270 & 360 & 1 \\
& & &
\end{tabular}

${ }^{1}$ Taken from Udenfriend, Duggan, Vasta, and Brodie (1957); the maxima quoted are instrumental values. 
bonds and aromatic systems and for the side chains which contribute so much to fluorescence intensity; and also noting the presence of deactivating atoms or systems in the molecule and the possibility of ionization if $p \mathrm{H}$ changes were to be introduced into the medium. A list of some fluorescent natural compounds is given in Table VII, and of some drugs in Table VIII.

It is not possible, within the limits of the review, to deal with the fluorescent properties of all the compounds of importance in biochemistry and medicine, although several such compounds have already been referred to earlier in this text. However, in what follows some examples have been selected to illustrate the possibilities of fluorescence.

PYRIMIDINES AND PURINES These compounds are of considerable interest because of their occurrence in nucleic acids and nucleotides. If the structure of pyrimidine and purine is examined (see below), it will be seen that both molecules contain doubly bound nitrogen $(-\mathrm{N}=)$, and as stated earlier (see p. 375), such compounds might be expected to be nonfluorescent. However, as also stated earlier, the effects of these nitrogens could be overcome by

$$
\left(\begin{array}{c}
N_{1} \\
2
\end{array}\right.
$$

Pyrimidine<smiles>c1ncc2nc[nH]c2n1</smiles>

Purine

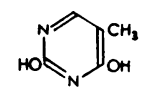

Thymine ( flu: $380 \mathrm{m \mu}$ at $\mathrm{pH} 11-13$ as anion) suitable substituents and by ionization. Udenfriend and Zaltzman (1962) have examined a number of pyrimidines $^{6}$ for fluorescence and found only thymine (2,4-dihydroxy-5-methylpyrimidine) to be fluorescent. The fluorescence of thymine was very weak and only occurred at $p \mathrm{H} 11$ to 13 where thymine exists as an anion.

Purine, however, is weakly fluorescent as an anion, and presumably the $>$ NH group when ionized is sufficiently electron-donating to overcome the effect of the doubly bound nitrogens in the ring system. Hypoxanthine, xanthine, and uric acid are

$$
\overbrace{N}^{N} \int_{\bar{N}}^{N} \begin{aligned}
& \text { Purine anion ( } f u \text { : } 370 m \mu \text { at } \\
& \text { pH 13) }
\end{aligned}
$$

non-fluorescent, but adenine and guanine and the nucleotides derived from them are fluorescent at certain $p \mathrm{H}$ values. Adenine is fluorescent only as the mono-cation. Adenosine, adenylic acid, adenosine diphosphate (ADP), and adenosine triphosphate (ATP) are also weakly fluorescent in

'Börresen (1963) has recently claimed that pyrimidine fluoresces weakly at high concentrations. This finding is contrary to accepted theory although Börresen has attempted to explain it. dilute acid solution, and in $5 \mathrm{~N}-\mathrm{H}_{2} \mathrm{SO}_{4}$ they are moreō fluorescent than adenine itself. Guanine is the most fluorescent of the natural purines, for its monocation and mono-anion are fluorescent. Its nucleo-o side and nucleotides, guanosine, guanylic acid,흐 guanosine diphosphate, and guanosine triphosphate, $\frac{\bar{s}}{\frac{}{2}}$ are also fluorescent (Udenfriend and Zaltzman, $\stackrel{\mathbb{Q}}{\not}$ 1962; Börresen, 1963). Guanosine and guanylic acid@ are fluorescent in acid solution, but they have very little fluorescence at $p \mathrm{H} 11$ where guanine is. appreciably fluorescent. These observations have $\vec{\omega}$ been used as the basis of a fluorimetric assay of 2 guanine in nucleic acid hydrolysates (Udenfriend용 and Zaltzman, 1962).

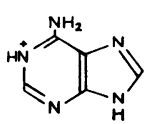

Adenine cation ( $\mathrm{flu}$ : $380 \mathrm{m \mu}$ at $\mathrm{pH} \mathrm{I)}$

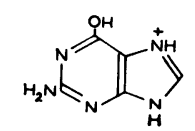

Guanine cation ( $f$ u $360 m \mu$ at $\mathrm{pH}$ J)

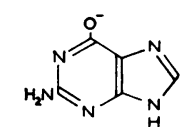

Guanine mono-anion ( $f u$ : $350 \mathrm{m \mu}$ at $\mathrm{pH}$ )

BARBITURATES An examination of the structural $\vec{\varphi}$ formula of a simple barbiturate (see below) shows that the molecule does not contain conjugated double bonds and is therefore unlikely to be fluorescent. In fact, barbiturates are not fluorescent in aqueous solution, but in $0 \cdot 1 \mathrm{~N}$ or $N-\mathrm{NaOH}$ some of them show appreciable fluorescence. Pheno- $\frac{}{\Phi}$ barbitone, pentobarbitone, amylobarbitone, and the thiobarbiturates, thiopental and surital, are fluor-을 escent at $p \mathrm{H} 13$ to 14 (Udenfriend, Duggan, Vasta, and Brodie, 1957). Barbiturates have two pKa's, one

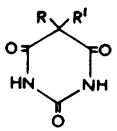

Barbiturate unionized (r.onfluorescent)<smiles>[R]C1([R])C(=O)N=C([O-])N=C1[O-]</smiles>

Barbiturate di-anion ( $f u$ : $440 \mathrm{m \mu}$ ) Thiobarbiturate di-anion

( flu: $530 \mathrm{m \mu}$ )

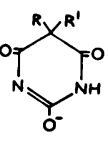

Barbiturate mono-anion (non-fluorescent)<smiles>[R]C1([R])CN=C([CH])N=C1[O-]</smiles>

in the region of 7 to 8 corresponding to the formation of a mono-anion, and the other in the region of 12 to 13 corresponding to the formation of the di-anion (Butler, Ruth, and Tucker, 1955). Since the? fluorescence of the barbiturates occurs at $p \mathrm{H} 13$ to 14, , the fluorescent species is probably the di-anion.은 Probably the two ionized $\mathrm{OH}$ groups opposing thes two doubly bound nitrogens are the main contribu- $-\overrightarrow{\mathbb{D}}$ tors in producing the conditions responsible foro fluorescence. The thiobarbiturate fluorescence is also probably due to a di-anion (see above). It occurs at ac 
longer wavelength $(530 \mathrm{~m} \mu)$ than the barbiturate fluorescence $(440 \mathrm{~m} \mu)$. $N$-Substituted barbiturates such as $N$-methyl-phenobarbitone are unable to form a di-anion and are probably not fluorescent.

PYRIDINE NUCLEOTIDES Nicotinamide is nonfluorescent and this agrees with the fact that its molecule contains doubly bound nitrogen and the meta-directing carbamyl group both of which would tend to produce a non-fluorescent molecule. The

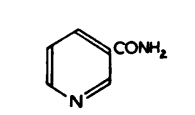

Nicotinamide (non-fuorescent)

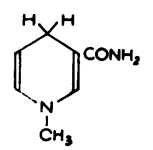

4-Hydro-Nmethylnicotinamide<smiles>NC(=O)C1=CN(CCCC(=O)OCc2ccccc2)CCC1</smiles>

Fluorescent form of

NADH (exc. 260, 340 $m \mu, f u: 457 m \mu)$

oxidized forms of the pyridine nucleotides $\left(\mathrm{NAD}^{+}\right.$ and $\mathrm{NADP}^{+}$) are also non-fluorescent, but the reduced forms (NADH and NADPH) are fluorescent, a property which has been used for the assay of a number of dehydrogenases, including lactic, glutamic, and malic dehydrogenases, and to study the oxidation-reduction mechanisms of intact cells and subcellular particules (Lowry, Roberts, and Kapphahn, 1957; Lowry, Roberts, and Lewis, 1956; Duysens and Amesz, 1957; Duysens and Sweep, 1957; Chance and Baltscheffsky, 1958; Chance and Legallais, 1959). The components of these coenzymes (NADH and NADPH) are adenine, reduced nicotinamide, ribose, and phosphate. The reduced form of $N$-methylnicotinamide is fluorescent (excitation, $360 \mathrm{~m} \mu$, and fluorescent, $468 \mathrm{~m} \mu$ ) and the fluorescent form of this molecule as proposed by Weber (1958) is shown above. Adenine is also fluorescent. The corrected excitations of NADH in aqueous solution are at 260 and $340 \mathrm{~m} \mu$, and the fluorescence is at $457 \mathrm{~m} \mu$ (Weber, 1957). The $260 \mathrm{~m} \mu$ excitation is due to the adenine moiety and the fluorescence resulting from it is due to energy transfer from the purine portion of the molecule to the substituted dihydronicotinamide portion, the excitation of which is at $340 \mathrm{~m} \mu$. The fluorescent form of NADH proposed by Weber is shown above.

The oxidized forms of the pyridine nucleotides can be induced to fluoresce by heating with alkali (Kaplan, Colowick, and Barnes, 1951; Lowry et al.,
1957), and this procedure can be adapted to measure both the oxidized and reduced coenzymes fluorimetrically. Fluorimetric methods have also been devised for $N$-methylnicotinamide, by condensation with ketones in the presence of alkali to give highly fluorescent products (Udenfriend, 1962, for references).

PORPHYRINS The basic ring system in the porphyrins is that of porphin, which, as can be seen from its structure, contains the necessary conjugated double bonds which give rise to fluorescence. Porphyrins in acid solution and in organic solvents are, in fact, highly fluorescent, the fluorescence

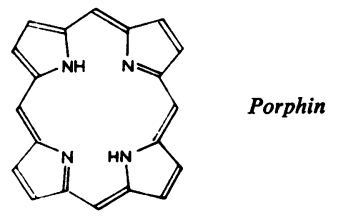

occurring in the red and infrared regions of the spectrum. However, it is important to note that the biologically active forms of porphyrins in animals, that is, the metalloporphyrins containing iron and copper, are non-fluorescent. When these metals are removed fluorescence appears. Chlorophyll, on the other hand, is a magnesium porphyrin which is fluorescent in water and alcohol (for details of porphyrin fluorescences, see Vannotti, 1954; and Udenfriend, 1962).

Porphyrins show several fluorescent bands but the principal bands in pyridine are the following:-

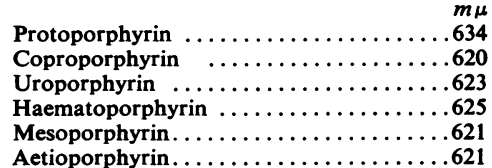

When haemoglobin undergoes degradation in the body, one of the products is urobilinogen. In this compound, the methine bridges $(-\mathrm{CH}=)$ which occur in the original porphin structure have been reduced so that the conjugated double bond system has been destroyed. Urobilinogen is, therefore, non-fluorescent. However, if it is oxidized to urobilin, conjugation is partly restored, and urobilin is fluorescent.

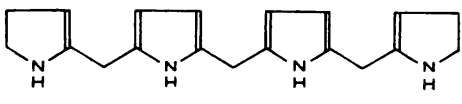

Urobilinogen ring system (non-fluorescent)

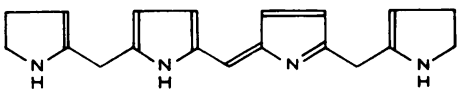

Urobilin ring system (diffuse fluorescence, 600-640 $\mathrm{m \mu}$ ) 
PYRIDOXINE AND RELATED COMPOUNDS Pyridoxine (vitamin $\mathbf{B}_{6}$ ), pyridoxal, pyridoxal 5-phosphate, and pyridoxamine play an important role in the activity of several enzymes, e.g., transaminases, decarboxylases, etc. These compounds are derivatives of 3-pyridol and they show very interesting fluorescence changes at different $p \mathrm{Hs}$ (Bridges et al., 1963). The fluorescence characteristics of the

$$
\begin{array}{ll}
\text { 3-Pyridol } \\
\mathrm{OH}
\end{array} \begin{aligned}
& \begin{array}{l}
\text { Pyridoxine; } \mathrm{R}_{1}=\mathrm{R}_{2}=\mathrm{CH}_{2} \mathrm{OH} \\
\text { Pyridoxal } \mathrm{R}_{1}=\mathrm{CHO} ; \mathrm{R}_{2}=\mathrm{CH}_{2} \mathrm{OH}
\end{array} \\
& \begin{array}{l}
\mathrm{CH}_{2} \mathrm{OPO} \mathrm{H}_{3} \mathrm{H}_{2} \\
\text { Pyridoxamine; } ; \mathrm{R}_{1}=\mathrm{CHO} ; \mathrm{R}_{2}=\mathrm{CH}_{2} \mathrm{NH}_{2} ; \mathrm{R}_{2}= \\
\mathrm{CH} \mathrm{H}_{2} \mathrm{OH}
\end{array}
\end{aligned}
$$

pyridoxine series formulated above are similar to those of 3-pyridol and it will be simpler to describe the fluorescences of the latter than to describe the detailed fluorescences of the pyridoxine compounds. 3-Pyridol can occur at different $p \mathrm{H}$ values in four different forms each having a characteristic fluorescence:-

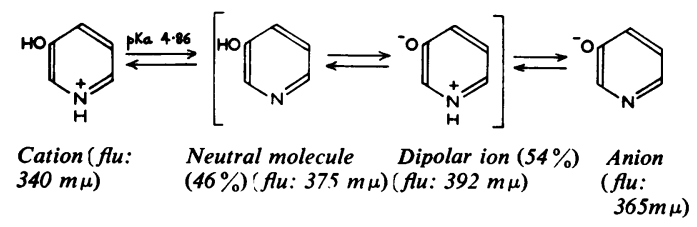

The cation, neutral molecule, and dipolar ion of 3-pyridol are only weakly fluorescent, but the anion is strongly fluorescent, its intensity being 50 times that of the cation and 16 times that of the dipolar ion. The cation shows excited state ionization, so that at $p \mathrm{H}$ values more than -1 up to 7 , it shows the fluorescence of the dipolar ion. The true fluorescence of the cation, i.e., at $340 \mathrm{~m} \mu$, is only shown at $p \mathrm{H}-1(10 \mathrm{~N}-\mathrm{HCl})$ and less. The unexcited cation ionizes to the dipolar ion at $p \mathrm{H} 4$ to 5 (pKa 4.86), so that in the excited state (pKa -0.95$)$ the cation is about a million times weaker as a base than in the unexcited state.

The phenomenon of excited state ionization is also shown by the cations of pyridoxine, pyridoxal and its phosphate, and pyridoxamine. However, all the forms of these compounds are more fluorescent than the corresponding forms of 3-pyridol. The most fluorescent forms of pyridoxine and of pyridoxamine are the corresponding dipolar ions (see Table IX) whereas those of pyridoxal and its phosphate are the anions. In the case of pyridoxal the most fluorescent form is probably the anion of the cyclic hemiacetal of pyridoxal, and in the case of pyridoxal phosphate it is probably the tri-anion of the aldehyde hydrate of pyridoxal phosphate (see Table IX). At high $p \mathrm{H}$ values (12 to 14) pyridoxal phosphate shows two fluorescences, one at $370 \mathrm{~m} \mu$ corresponding to the tri-anion of the hydrate, and another, eight times less intense, at $525 \mathrm{~m} \mu$ which appears to correspond to the tri-anion of the free aldehyde form of pyridoxal phosphate. 3-Pyridol is

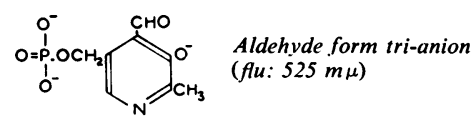

stable in ultraviolet light but pyridoxine and its 용 three congeners show photo-decomposition so that measurements of fluorescence have to be made is within 30 seconds of exposure to the exciting light.

The fluorimetric assay of these compounds in biological materials is carried out by oxidation to the highly fluorescent pyridoxic acid which is eventually converted into its lactone which, at $p \mathrm{H} 9$, is some 25 times more fluorescent than the acid (Huff and Perlzweig, 1944; Reddy, Reynolds, and Price, 1958).

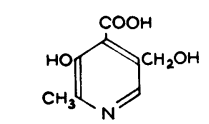

Pyridoxic acid (no distinct fluorescence peak)

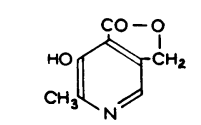

Pyridoxic acid lactone (flu: $450 \mathrm{m \mu}$ )
PROTEIN FLUORESCENCE AND FLUORESCENCE POLARIZATION The study of the fluorescence of proteins is a difficult but interesting field and up to the present it has hardly been exploited. Here it is intended but to mention a few of its simpler aspects and for further information the reader is referred to Chapter 6 of the book by Udenfriend (1962) and to reviews and papers by Weber and his associates (e.g., Weber, 1953; Weber, 1960 a, b; Teale, 1960; see also Udenfriend, 1962, for other references).

Simple proteins absorb light in the region 270-300 $\mathrm{m} \mu$ and this absorption is due mainly to the aromatic amino-acids, tyrosine and tryptophan. Proteins containing these amino-acids could therefore be expected to fluoresce. In addition to these amino-acids, proteins frequently contain phenylalanine which is also fluorescent, but its fluorescence is much weaker than that of the other two. The fluorescence maxima and quantum efficiencies (Q.E.) of these acids in neutral aqueous solution are: tryptophan, $\lambda \max .348 \mathrm{~m} \mu$, Q.E. $20 \%$; tyrosine, $\lambda \max .303 \mathrm{~m} \mu$, Q.E. $21 \%$; and phenylalanine, $\lambda \max .282 \mathrm{~m} \mu$, Q.E. $4 \%$ (Teale and Weber, 1957). A large number of proteins have been found to fluoresce (Shore and Pardee, 1956; Konev, 1957). Those containing phenylalanine and tyrosine but no tryptophan show a maximum emission at $303 \mathrm{~m} \mu$, 
TABLE IX

MOST INTENSELY FLUORESCENT FORMS OF PYRIDOXINE AND ITS DERIVATIVES

(5 $\mu \mathrm{g} . / \mathrm{ml}$.) AND EXCITED pKa's OF THE CATIONS

(BRIDGES, DAVIES, AND WILLIAMS, 1963)

\begin{tabular}{|c|c|c|c|c|c|c|}
\hline \multirow{2}{*}{ Compound } & \multirow{2}{*}{ Mos: Fluorescent Form } & \multirow{2}{*}{$\begin{array}{l}\text { Excitation }^{1} \\
\text { Maximum }(m \mu)\end{array}$} & \multirow{2}{*}{$\begin{array}{l}\text { Fluorescence }^{1} \\
\operatorname{Maximum}(m \mu)\end{array}$} & \multirow{2}{*}{$\begin{array}{l}\mathrm{pH} \text { of Maximum } \\
\text { Fluorescence }\end{array}$} & \multicolumn{2}{|c|}{$p K a$ of Cation } \\
\hline & & & & & Unexcited $^{2}$ & Excited $^{3}$ \\
\hline 3-Pyridol & & 309 & 365 & $10-14$ & $4 \cdot 86$ & -0.95 \\
\hline Py-idoxine & & 332 & 400 & $6-8$ & $4 \cdot 72$ & -0.8 \\
\hline Pyridoxal & & 310 & 365 & ca. 12 & $4 \cdot 22$ & -0.95 \\
\hline Pyridoxal 5'-phospkate & & 315 & 370 & $12-14$ & $4 \cdot 14$ & $<-0.3$ \\
\hline Pyridoxamine & & 337 & 400 & ca. 5 & 3.4 & -0.8 \\
\hline
\end{tabular}

${ }^{1}$ Uncorrected instrumental values.

${ }^{2}$ The pKa taken from Metzler and Snell (1955) and Albert (1960).

${ }^{3}$ Excited pKa's are approximate and deduced from $\mathrm{pH} /$ fluorescence intensity curves.

whilst those containing tryptophan show a maximum in the region of 320 to $350 \mathrm{~m} \mu$ (Teale, 1960; see Table X). The $303 \mathrm{~m} \mu$ emission is due to tyrosine and the 320 to $350 \mathrm{~m} \mu$ emission to tryptophan. The tryptophan-containing proteins apparently do not show an emission due to tyrosine which is in some way quenched for there is no energy transfer from tyrosine to tryptophan in the protein. No fluorescence due to the phenylalanine residue has been observed.

A large number of natural proteins contain prosthetic groups, which can have a profound influence on the fluorescence of the protein. These groups include metals, porphyrins, coenzymes, and carbohydrates. If the prosthetic group is capable of absorbing light, it can either enhance or diminish the fluorescence of the protein or it can endow the conjugated protein with its own fluorescence. Usually, haem proteins are non-fluorescent because the excitation energy absorbed by the protein is transferred to the haem portion of the molecule
TABLE X

NATIVE FLUORESCENCE OF PROTEINS IN WATER (TEALE, 1960)

Protein

$\lambda$ Maximum $(m \mu)$

$\begin{array}{lc}\text { A Containing phenylalanine and tyrosine but no tryptophan } \\ \text { Insulin } & 304 \\ \text { Ovomucoid } & 304 \\ \text { Ribonuclease } & 304 \\ \text { Zein } & 304\end{array}$

$B$ Containing phenylalanine, tyrosine, and tryptophan Edestin 328

Bovine $\gamma$-globulin

Ovalbumin

Trypsin

Trypsinogen

Chymotrypsin

Chymotrypsinogen

Haemoglobin globin

Fumarase

Fibrinogen

Human serum albumin

Carboxypeptidase

Lysozyme

Bovine serum albumin

Pepsin 
where it is degraded (Weber and Teale, 1959) (see p. 384). In the case of proteins conjugated with the reduced pyridine nucleotides (e.g., alcohol, lactic, glutamic and malic dehydrogenases) the effect of the prosthetic group is to endow the protein with its own fluorescence which is often intensified and shifted to shorter wavelengths (Shifrin and Kaplan, 1960).

Fluorescent molecules can also be combined with proteins to give highly fluorescent conjugates which can be used for many purposes such as the assay of serum proteins and the distribution of antigens and various proteins in tissues (Udenfriend, 1962).

One aspect of fluorescence which is of particular application to the study of proteins is fluorescence polarization. This phenomenon can be explained as follows. Light consists of waves whose amplitude in all planes is at right angles to the light path. Light is plane polarized if its waves are in one plane only and this polarization can be achieved with a Nicol prism. If molecules are excited by plane polarized light, then those molecules whose axes happen to be orientated in a direction parallel to the light path are preferentially excited. If these molecules are in a rigid medium, the fluorescence they emit will be plane polarized, i.e., the waves are in one plane only. However, if the medium is not rigid, the excited molecules may be able to rotate about their axes before the fluorescence is emitted. In this case the fluorescence will be partially polarized or nonpolarized depending upon the rate at which the excited molecules rotate, the life time of the excited state, and the viscosity of the medium or solvent. The time taken for these excited molecules to disorientate completely is called the relaxation time. Each fluorescent molecule has a characteristic relaxation time for a given solvent under given conditions. For small molecules in low viscosity solvents the relaxation time is short compared with the life time of the excited state $\left(10^{-8}\right.$ second) so that no polarized fluorescence is observed with such $\vec{\circ}$ molecules when they are excited by plane polarized light. Large molecules such as proteins, however, may emit polarized fluorescence since their relaxation times are long compared with the life time of the excited state. The degree of polarization can be measured with a suitable Nicol prism analyzer and $c$ from this the relaxation time of the molecule can be $د$ estimated.The relaxation time gives useful inform- 은 ation about the physical characteristics, e.g., shape and size, of a macromolecule. If the macromolecule $\subseteq$ is one which has no native fluorescence, its relaxation time could still be measured provided it can be $\vec{\varphi}$ conjugated with a small fluorescent molecule (see $\stackrel{\varnothing}{\oplus}$ Weber, 1953; Laurence, 1957).

ADDITIONAL REFERENCES ON COMPOUNDS OF BIOLOGICAL INTEREST Many references to the applications of fluorescence methods in biology and medicine are given in the book by Udenfriend (1962). In addition to these, the following list of recent references may be quoted.

\section{NATURAL PRODUCTS AND THEIR DERIVATIVES}

Estrone, $\beta$-estradiol, cortisone and related compounds

17 $\alpha$ substituted steroids
Methandrostenolone
Bile acids
Coproporphyrin
Phospholipids
Glycerol
Acetone
Malonaldehyde
Coumarins
Anthranilic acid
Hippuric acid
Carbohydrates
Adrenaline, noradrenaline
Total catecholamines
5-Hydroxy-and 5-methoxy-indoles
Serotonin
Histamine
Tetrahydrofolate and related compounds
Pyridoxamine
NADP
Phenylalanine
2-Dimethylamino-6-hydroxypurine
Guanine

Ichii, Forchielli, Perloff, and Dorfman (1963)

Rudd, Cowper, and Crawford (1961)

Stewart, Albert-Recht, and Osman, 1961)

De Moor, Osinski, Deckx, and Steeno (1962)

Mattingly, (1962)

Steinetz, Beach, Dubnick, Meli, and Fujimoto (1963)

Tishler, Sheth, Giaimo, and Mader (1962)

Levin and Johnston (1962)

Mentz and Grotepass (1960)

Harris and Gambal (1963)

Mendelsohn and Antonis (1961)

Hynie, et al., (1960)

Sawicki, Stanley, and Johnson (1963)

Crosby and Berthold (1962)

Sanders and Parks (1962)

Ellman, Burkhalter, and LaDou (1961)

Towne and Spikner (1963)

Merrills (1963)

$\{$ Jacobs, Sobel, and Henry (1961)

Mahler and Humoller (1962)

Small (1963)

Quay (1963)

$\{$ Crosti and Luchcelli (1962)

Crawford and Rudd (1962)

Noah and Brand (1961)

$\{$ Zachariae (1963)

Uyeda and Rabinowitz (1963)

Toepfer, Polansky, and Hewston (1961)

Estabrook (1962)

McCaman and Robins (1962)

Udenfriend, Zaltzman-Nirenberg, and Cantoni (1963)

Udenfriend and Zaltzman (1962) 
$\gamma$-Globulins

Plasma proteins

Fibrinolysin

Lactic dehydrogenase

Lipase

$\Delta^{5}$-3-Ketosteroid isomerase

Drugs

Digitoxin and digoxin

Emetine hydrochloride

Reserpine

Chlordiazepoxide (librium)

Benzoquinolizines

Phenothiazines

Tetracyclines

Oxytetracycline

Acriflavine

Mechlorethamine (mustargen)

Isoniazid

Metals in biological material

Selenium

Calcium

Magnesium, calcium, and zinc

Magnesium
Sokol, Hana, and Albrecht (1961)

Hiraoka and Glick (1963)

Pappenhagen, Koppel, and Olwin (1962)

Laursen (1962)

Kramer and Guilbault (1963)

Wang, Kawahara, and Talalay (1963)

\section{Jakovljevic (1963)}

Ichimura (1961)

Tishler, Sheth and Giaimo (1963)

Koechlin and D'Arconte (1963)

Schwartz and Rieder (1961)

Mellinger and Keeler (1963)

Worsley, McKenna, and Beck (1963)

Ibsen, Saunders, and Urist (1963)

Bićan-Fišter (1960)

Mellett and Woods (1960)

Peters (1960)

Dye, Bretthauer, Seim, and Blincoe (1963)

Kepner and Hercules (1963)

$\{$ Wallach and Steck (1963)

Hofman (1961)

Watanabe, Frantz, and Trottier (1963)

Schachter (1961)

\section{REFERENCES}

Albert, A. (1960). J. chem. Soc., P. 1020.

Bićan-Fišter, T. (1960). Acta pharm. jugosl., 10, 161. (Chem. Abstr. (1961). 55, 14820c.)

Börresen, Hans Chr. (1963). Acta chem. scand., 17, 921.

Bowen, E. J., and Wokes, F. (1953). Fluorescence of Solutions. Longmans, Green, London

Bowman, R. L., Caulfield, P. A., and Udenfriend, S. (1955). Science, $122,32$.

Bridges, J. W. (1963). Ph.D. Thesis, University of London.

- Creaven, P. J., and Williams, R. T. (1963). Unpublished data. _, Davies, D. S., and Williams, R. T. (1963). Biochem J. 88, 65P.

_- Davies, D. S., and Williams, R. T. (1963). Unpublished data.

- and Williams, R. T. (1962). Nature (Lond.), 196, 59.

,,-- (1963). Unpublished data.

Brodie, B. B., Udenfriend, S., Dill, W., and Chenkin, T. (1947). J. biol. Chem., 168, 319.

Butler, T. C., Ruth, J. M., and Tucker, G. F. (1955). J. Amer. chem. Soc., 77, 1486.

Chance, B., and Baltscheffsky, H. (1958). J. biol. Chem., 233, 736 , and Legallais, V. (1959). Rev. sci. Instr., 30, 732.

Cleveland, F. F. (1955). Raman Spectra In Determination of Organic Structures by Physical Methods, edited by E. A. Braude and F. C. Nachod, p. 231. Academic Press, New York.

Cowgill, R. W. (1963). Arch. Biochem., 100, 36.

Crawford, N., and Rudd, B. T. (1962). Clin. chim. Acta, 7, 114.

Crosby, D. G., and Berthold, R. V. (1962). Analyt. Biochem., 4, 349.

Crosti, P. F., and Lucchelli, P. E. (1962). J. clin. Path., 15, 191.

De Moor, P., Osinski, P., Deckx, R., and Steeno, O. (1962). Clin. chim. Acta, 7, 475.

Duggan, D. E., Bowman, R. L., Brodie, B. B., and Udenfriend, S. (1957). Arch. Biochem., 68, 1.

- and Udenfriend, S. (1956). J. biol. Chem., 223, 313.

Duysens, L. N. M., and Amesz, J. (1957). Biochim. biophys. Acta (Amst.), 24, 19.

- and Sweep, G. (1957). Ibid., 25, 13.

Dye, W. B., Bretthauer, E., Seim, H. J., and Blincoe, C. (1963). Analyt. Chem., 35, 1687.

Ellman, G. L., Burkhalter, A., and LaDou, J. (1961). J. Lab. clin. Med., $57,813$.

Estabrook, R. W. (1962). Analyt. Biochem., 4, 231.

Feigl, F., Feigl, H. E., and Goldstein, D. (1955). J. Amer. chem. Soc., 77,4162

Förster, T. (1950). Z. Elektrochem., 54, 531.

Hagins, W. A., and Jennings, W. H. (1959). Disc. Faraday Soc., no. 27, 180.

Harris, R. A., and Gambal, D. (1963). Analyt. Biochem., 5, 479.
Hercules, D. M., and Rogers, L. B. (1959). Spectrochim. Acta, 14, 393. Hiraoka, T., and Glick, D. (1963). Analyt. Biochem., 5, 497.

Hofman, J. (1961). Cas. Lék. čes., 100, 1171.

Huff, J. W., and Perlzweig, W. A. (1944). J. biol. Chem., 155, 345.

Hynie, I., Věerek, B., and Wágner, J. (1960). Čas. Lék. čes., 99, 88.

Ibsen, K. H., Saunders, R. L., and Urist, M. R. (1963). Analyt. Biochem., 5, 505.

Ichii, S., Forchielli, E., Perloff, W. H., and Dorfman, R. I. (1963). Ibid., 5, 422.

Ichimura, Y. (1961). Bunseki Kagaku, 10, 623. (Chem. Abstr. (1962). $56,1530 \mathrm{e}$.)

Jacobs, S. L., Sobel, C., and Henry, R. J. (1961). J. clin. Endocr., 21, 305.

Jakovljevic, I. M. (1963). Analyt. Chem., 35, 1513.

Kaplan, N. O., Colowick, S. P., and Barnes, C. C. (1951). J. biol. Chem., 191, 461.

Kasha, M. (1960). Radiat. Res., suppl., 2, 243.

Kepner, B. L., and Hercules, D. M. (1963). Analyt. Chem., 35, 1238.

Kerr, V. N., Hayes, F. N., and Ott, D. G. (1957). Int. J. appl. Radiat., $1,284$.

Koechlin, B. A., and D'Arconte, L. (1963). Analyt. Biochem., 5, 195.

Kohn, K. W. (1961). Analyt. Chem., 33, 862.

Konev, S. V. (1957). Dok. Akad. Nauk SSSR Otd. Biokh., 116, 594.

Kramer, D. N., and Guilbault, G. G. (1963). Analyt. Chem., 35, 588.

Kuhn, R., Wagner-Jauregg, T., and Kaltschmitt, H. (1934). Ber. dtsch. chem. Ges., 67, 1452.

Laurence, D. J. R. (1957). In Methods of Enzymology, edited by S. P. Colowick and N. O. Kaplan, vol. IV, p. 174. Academic Press, New York.

Laursen, T. (1962). Scand. J. clin. Lab. Invest., 14, 152.

Levin, S. J., and Johnston, C. G. (1962). J. Lab. clin. Med., 59, 681.

Lippert, E., Lüder, W., and Moll, F. (1959). Spectrochim. Acta, 10, 858

Livingston, R., Watson, W. F., and McArdle, J. (1949). J. Amer. chem. Soc., 71, 1542.

Lowry, O. H., Roberts, N. R., and Kapphahn, J. I. (1957). J. biol. Chem., 224, 1047.

,- , and Lewis, C. (1956). Ibid., 220, 879.

Mahler, D. J., and Humoller, F. L. (1962). Clin. Chem., 8, 47.

Mattingly, D. (1962). J. clin. Path., 15, 374.

McCaman, M. W., and Robins, E. (1962). J. Lab. clin. Med., 59, 885.

Mellett, L. B., and Woods, L. A., (1960). Cancer Res., 20, 518.

Mellinger, T. J., and Keeler, C. E. (1963). Analyt. Chem., 35, 554.

Mendelsohn, D., and Antonis, A. (1961). J. Lipid Res., 2, 45.

Mentz, H. E. A., and Grotepass, W. (1960). S. Afr. J. Lab. clin. Med., 6, 43.

Merrills, R. J. (1963). Analyt. Biochem., 6, 272.

Metzler, D. E., and Snell, E. E. (1955). J. Amer. Chem. Soc., 77, 2431

Noah, J. W., and Brand, A. (1961). J. Allergy, 31, 236.

Ott, D. G., Hayes, F. N., Hansbury, E., and Kerr, V. N. (1957). J. Amer. chem. Soc., 79, 5448. 
Pappenhagen, A. R., Koppel, J. L., and Olwin, J. H. (1962). J. Lab. clin. Med., 59, 1039.

Parker, C. A. (1959). Analyst, 84, 446.

, and Barnes, W. J. (1957). Ibid., 82, 606.

- _, and Rees, W. T. (1962). Ibid., 87, 83.

Peters, J. H. (1960). Amer. Rev. resp. Dis., 81, 485.

Porter, G., and Weber, G. (1959). Nature (Lond.), 184, 688.

Quay, W. B. (1963). Analyt. Biochem., 5, 51.

R.C.A. Tube Handbook, HB-3. Radio Corporation of America, Electron Tube Division, Harrison, New Jersey.

Reddy, S. K., Reynolds, M. S., and Price, J. M. (1958). J. biol. Chem., 233, 691 .

Rosen, A., and Williams, R. T. (1961). Bull. photoelect. Spectrom. Grp, no. 13, 339.

Rudd, B. T., Cowper, J. M., and Crawford, N. (1961). Clin. chim. Acta, 6, 686.

Sanders, P. P., and Parks, L. W. (1962). Analyt. Biochem., 3, 354.

Sawicki, E., Stanley, T. W., and Johnson, H. (1963). Analyt. Chem., $35,199$.

Schachter, D. (1961). J. Lab. clin. Med., 58, 495.

Schwartz, D. E., and Rieder, J. (1961). Clin. chim. Acta, 6, 453.

Shifrin, S., and Kaplan, N. O. (1960). Advanc. Enzymol., 22, 337.

Shore, V. G., and Pardee, A. B. (1956). Arch. Biochem., 60, 100.

Small, N. A. (1963). Clin. chim. Acta, 8, 803.

Sokol, F., Hana, L., and Albrecht, P. (1961). Folia Microbiol. (Praha), 6,145 .

Steinetz, B. G., Beach, V. L., Dubnick, B., Meli, A., and Fujimoto, G. (1963). Steroids, 1, 395.

Stewart, C. P., Albert-Recht, F., and Osman, L. M. (161). Clin. chim. Acta, 6, 696.

Szent-Györgyi, A. E. (1957). Bioenergetics. Academic Press, New York.

Teale, F. W. J. (1960). Biochem. J., 76, 381

-, and Weber ,G. (1957). Ibid., 65, 476.
Tishler, F., Sheth, P. B., and Giaimo, M. B. (1963). J. Ass. off. agric. $\stackrel{\stackrel{2}{\rightleftharpoons}}{\frac{0}{2}}$ Chem., 46, 448 .

- - - - - and Mader, W. J. (1962). J. pharm. Sci., 51, 1175.

Toepfer, E. W., Polansky, M. M., and Hewston, E. M. (1961). Analyt. Biochem., 2, 463.

Towne, J. C., and Spikner, J. E. (1963). Analyt. Chem., 35, 211.

Udenfriend, S. (1962). Fluorescence Assay in Biology and Medicine. Academic Press, New York.

- Duggan, D. E., Vasta, B. M., and Brodie, B. B. (1957). J. Pharmacol. exp. Ther., 120, 26.

and Zaltzman, P. (1962). Analyt. Biochem., 3, 49.

, Zaltzman-Nirenberg, P., and Cantoni, G. L. (1963). Ibid., 5, 258.

Uyeda, K., and Rabinowitz, J. C. (1963). Ibid., 6, 100.

Van Duuren, B. L. (1963). Chem. Rev., 63, 325.

Vannotti, A. (1954). Porphyrins-Their Biological and Chemical-1 Importance, translated by C. Rimington, p. 20. Hilger and $\vec{c}$ Watts, London.

Wallach, D. F. H., and Steck, T. L. (1963). Analyt. Biochem., 6, 176.

Wang, S., Kawahara, F. S., and Talalay, P. (1963). J. biol. Chem., 응 238, 576.

Watanabe, S., Frantz, W., and Trottier, D. (1963). Analyt. Biochem., $\vec{V}$ $5,345$.

Weber, G. (1953). Advanc. Protein Chem., 8, 415.

- (1957). Nature (Lond.), 180, 1409.

(1958). J. Chim. Phys., 55, 878.

(1960a). Biochem. J., 75, 335.

(1960b). Ibid., 75, 345.

-, and Teale, F. W. J. (1959). Disc. Faraday Soc., no. 27, 134

Weil-Malherbe, H. (1946). Biochem. J., 40, 363.

White, A. (1959). Ibid., 71, 217.

Williams, R. T. (1959). J. roy. Inst. Chem., 83, 611.

Worsley, G. H., McKenna, R. D., and Beck, I. T. (1963). Canad. med. Ass. J., 88, 1272.

Zachariae, H. (1963). Scand. J. clin. Lab. Invest., 15, 173. 